\title{
Effects of Turbulence on Tidal Turbines: Implications to Performance, Blade loads, and Condition Monitoring
}

Tom Blackmore: T.Blackmore@soton.ac.uk

\author{
Luke Myers
}

AbuBakr S Bahaj

Sustainable energy Research Group, Energy and Climate Change Division, Faculty of Engineering and the Environment, University of Southampton, Southampton, SO17 1BJ, UK.

\begin{abstract}
Laboratory scale testing of tidal turbines has generated valuable datasets to support optimised turbine design and numerical model validation. However, tidal sites are highly turbulent with a broad range of length scales and turbulence intensities that are site specific. In this work we describe an experimental campaign using static grids to generate turbulence and investigate its impact on a model tidal turbine in a circulating water flume. Length scales, energy spectra and turbulence dissipation rates are first considered for centre point measurements before full flow characterisation of the ambient conditions across the turbine rotor area. Six different cases were chosen to observe the performance of a $1 / 20^{\text {th }}$ scale $0.8 \mathrm{~m}$ diameter turbine subjected to these flows. The rotor thrust and torque, and flapwise and edgewise blade root bending moments were measured. It was found that the thrust and power coefficients were sensitive to the estimate of ambient velocity. In the most extreme case the Betz limit could be 'exceeded' depending on which estimate of ambient velocity was used. Overall variations in the peak power coefficient of over $10 \%$ were observed, demonstrating the significance turbulence has on turbine performance. It was also found that there is a strong correlation between fluctuations in blade root bending moments and the rotor loads. As a result we proposed that fatigue loads acting on the blades may be estimated from the fluctuations in power output of the turbine. Therefore maintenance operations maybe optimised from real-time fatigue monitoring of blade loads without the need to install additional instrumentation on the turbine blades. Under this proposed regime the cost of energy will be reduced due to reductions in turbine costs and following optimisation of the maintenance requirements and operational costs. This could also improve turbine reliability which would have significant implications for large multi turbine arrays.
\end{abstract}

1 Nomenclature

\begin{tabular}{|c|c|l|}
\hline Symbol & Units & \multicolumn{1}{|c|}{ Description } \\
\hline $\mathrm{U}, \mathrm{V}$ & $\mathrm{m} / \mathrm{s}$ & Mean axial and transverse velocity \\
\hline $\mathrm{u}(\mathrm{t}), \mathrm{v}(\mathrm{t})$ & $\mathrm{m} / \mathrm{s}$ & Instantaneous axial and transverse velocity \\
\hline $\mathrm{u}^{\prime}(\mathrm{t}), \mathrm{v}(\mathrm{t})$ & $\mathrm{m} / \mathrm{s}$ & Fluctuation of axial and transverse velocity \\
\hline $\mathrm{I}$ & $\%$ & Turbulence intensity \\
\hline $\mathrm{R}(\mathrm{s})$ & - & Autocovarience function \\
\hline $\mathrm{s}$ & $\mathrm{s}$ & Time lag \\
\hline$\tau$ & $\mathrm{s}$ & Integral time scale \\
\hline$\ell$ & $\mathrm{m}$ & Integral length scale \\
\hline$x$ & $\mathrm{~m}^{-1}$ & Wavenumber \\
\hline $\mathrm{L}$ & $\mathrm{M}$ & Turbulence length / eddy size \\
\hline $\mathrm{S}(\omega)$ & $(\mathrm{m} / \mathrm{s})^{2} / \mathrm{s}$ & Power spectral density in the time domain \\
\hline$\omega$ & $\mathrm{Rad} / \mathrm{s}$ & Angular speed \\
\hline $\mathrm{S}(x)$ & $(\mathrm{m} / \mathrm{s})^{2} / \mathrm{m}^{-1}$ & Power spectral density in wavenumber space \\
\hline $\mathrm{S} \mathrm{c}(x \eta)$ & $\left(\mathrm{m} / \mathrm{s}^{3} \mathrm{~s}^{-1 / 3}\right.$ & Compensated energy spectrum \\
\hline $\mathrm{E}$ & $\mathrm{j}$ & Energy \\
\hline $\mathrm{k}$ & $\mathrm{m}^{2} / \mathrm{s}^{2}$ & Kinetic energy \\
\hline$\varepsilon$ & $\mathrm{m}^{2} / \mathrm{s}^{3}$ & Turbulence dissipation rate \\
\hline$\nu$ & $\mathrm{m}^{2} / \mathrm{s}$ & Kinematic viscosity \\
\hline $\mathrm{E}(x)$ & $\mathrm{m}^{2} / \mathrm{s}^{2}$ & Energy spectrum \\
\hline$\ell_{\mathrm{d}}$ & $\mathrm{m}^{\mathrm{m}}$ & Dissipation length scale \\
\hline $\mathrm{C}$ & - & Kolmogorovs constant = 1.5 \\
\hline
\end{tabular}




\begin{tabular}{|c|c|l|}
\hline$\ell_{\mathrm{i}}$ & $\mathrm{m}$ & Injection length scale \\
\hline $\mathrm{b}$ & $\mathrm{m}$ & Grid bar width \\
\hline $\mathrm{X}$ & $\mathrm{m}$ & Downstream distance from grid \\
\hline $\mathrm{S}$ & - & Skewness \\
\hline $\mathrm{K}$ & - & Kurtosis \\
\hline\langle & - & Area average over rotor area \\
\hline & - & Time average \\
\hline $\mathrm{T}$ & $\mathrm{N}$ & Thrust force \\
\hline $\mathrm{P}$ & $\mathrm{W}$ & Power \\
\hline $\mathrm{C}_{\mathrm{T}}$ & - & Thrust coefficient \\
\hline $\mathrm{C}_{\mathrm{P}}$ & - & Power coefficient \\
\hline $\mathrm{X}_{1}$ & $\mathrm{~m} / \mathrm{s}$ & Time average velocity at hub height \\
\hline $\mathrm{X}_{2}$ & $\mathrm{~m} / \mathrm{s}$ & Time averaged velocity over rotor area \\
\hline $\mathrm{X}_{3^{\mathrm{n}}}$ & $(\mathrm{m} / \mathrm{s})^{\mathrm{n}}$ & Velocity raised to power $\mathrm{n}$, the time and area averaged \\
\hline $\mathrm{A}$ & $\mathrm{m}$ & Rotor area \\
\hline$\varrho$ & $\mathrm{Kg} / \mathrm{m}^{3}$ & Fluid density \\
\hline $\mathrm{C}_{\mathrm{MF}}$ & - & Coefficient of flapwise blade root bending moment \\
\hline $\mathrm{C}_{\mathrm{ME}}$ & - & Coefficient of edgewise blade root bending moment \\
\hline $\mathrm{M}_{\mathrm{F}}$ & $\mathrm{Nm}$ & Flapwise blade root bending moment \\
\hline $\mathrm{M}_{\mathrm{E}}$ & $\mathrm{Nm}$ & Edgewise blade root bending moment \\
\hline $\mathrm{R}$ & $\mathrm{m}$ & Rotor radius \\
\hline $\mathrm{D}$ & $\mathrm{m}$ & Rotor diameter \\
\hline $\mathrm{Q}$ & $\mathrm{Nm}$ & Torque \\
\hline $\mathrm{T}$ & - & Noise threshold of autocovarience \\
\hline & & \\
\hline
\end{tabular}




\section{Introduction}

From the initial concepts to the first pre-commercial tidal turbine prototypes one of the key requirements has been survivability and reliability [1]. Operating in a corrosive marine environment, under the ocean, with storm surges and waves, is not an easy task. This has been a steep learning curve with a number of device failures [2]-[5]. The current success is due to persistence and over engineering that provides large factors of safety. Clearly this is a sub-optimal solution when it comes to material usage and hence cost.

One topic that has received little consideration to date is the impact of turbulence on the performance and loadings acting on a tidal turbine. Turbulence describes the chaotic motions within a fluid flow and can result in fluctuations in force, which is detrimental to the fatigue life of the turbine. Turbulence has been identified as requiring further investigation for both single devices [6] and arrays of multiple devices [7]. Tidal flows are highly turbulent with a broad range of length scales, and intensities[8], [9]. Previous investigations have shown how the thrust coefficient, or mean (time averaged) thrust force, of a porous disc rotor simulator can vary by over $20 \%$ in turbulent flows with different turbulence characteristics [10]. Further, numerical simulations have shown how turbulence affects the wake recovery behind an actuator disc turbine representation [11]. Studies using model turbine rotors have also shown significant variations when operated in flows with different turbulence intensities [12]-[14]. It has been found that increasing turbulence intensity from 3-15\% typically reduces the power and thrust coefficients of a 3 bladed turbine rotor by roughly $5-10 \%$ [13]. Further studies have been performed on a turbine in uniform oscillatory flow using a towing tank with oscillating motion superimposed on the towing carriage[15], [16]. It was found that the out-of-plane blade root bending moments increased by around 15\% over the steady case [16]. This increase in load was attributed to flow separation around the blade [15]. This demonstrates that turbulence is likely to have a significant effect on both turbine performance and fatigue life, but further investigation is required.

In this work we aim to address some of the issue highlighted above. Here we present an experimental campaign to investigate the effects of turbulence on turbine performance and blade loadings. In previous studies the turbulence was typically characterised as a turbulence intensity and limited control provided by adding, or removing flow straighteners in the flume [13]. It is therefore likely that the scales of turbulence will also differ. In the other studies mentioned, planar oscillatory motion was superimposed on a turbine in a towing tank [15], [16]. This method provides control of the oscillations, but the resulting flow will differ from that of turbulence which would be 3 dimensional and contain chaotic motions which are correlated in both space and time. Static grids are commonly used to generate turbulent flows with different characteristics in wind tunnels [17], [18]. By changing the grid size the turbulence length scales can be changed, and by altering the distance downstream of the grid the turbulence intensity can be controlled as the turbulence is freely decaying [17]. This approach was first used by the authors in a series of small scale experiments in a gravity fed water flume using porous disc rotor simulators [10]. The same approach is used here using a large circulating water channel and a scale turbine in which we aim to consider the impacts of turbulence intensity and turbulence length scale on turbine performance and blade loads. Section 3 of the paper presents the method of using static grids to generate turbulence in laboratory flumes. Different turbulence statistics are considered in Section 4 (in particular, turbulence intensities and turbulence length scales), and the inflow conditions the turbine would experience are presented in Section 5. Six cases with different turbulence characteristics were chosen and a $1 / 20^{\text {th }}$ scale turbine was operated in the flows over a range of tip-speed-ratios (TSR). Section 6 presents the results from the turbine and discusses the mean, time averaged, rotor performance as well as their fluctuations. Flapwise and edgewise blade root bending moments are presented and their fluctuations compared to those of the rotor.

\section{Turbulence generation method}

The experimental method is based on the use of static grids to generate turbulence. This is common practice in wind tunnel experiments [19] but not so in circulating water flumes. The experimental method used for this work is based on the previous work at a smaller scale in a gravity fed flume $2 \mathrm{~m}$ wide and $0.6 \mathrm{~m}$ deep[10]. Velocity shear is generated behind the grid bars producing vortices, which in turn break down to produce turbulence. The size of vortices, or eddies, are proportional to the width of the grid bars, therefore a grid with larger bars will produce larger scales of turbulence. Progressing downstream from the grid the turbulence decays and the turbulent energy decreases following a power law [19]. Therefore the length scales of turbulence can be controlled by using different size grids, and the turbulent energy, or intensity can be controlled by moving further downstream from the grid. The key benefit of using grid 
generated turbulence is the control it allows over the generated turbulence characteristics in the flow that the turbine is operated in. Grid generated turbulence is also typically uniform and isotropic, therefore the turbine could be considered to be operating in a free-stream flow. This reduces additional factors that would be present in a tidal flow such as boundary effects (velocity shear) and turbulence anisotropy. This therefore allows the specific effects of turbulence length scale and intensity on turbine performance and blade loads to be investigated. In this work we are not recreating tidal specific turbulence and this is a topic for future consideration.

Experiments were performed in the IFREMER circulating water channel that has a working section $18 \mathrm{~m}$ long, $4 \mathrm{~m}$ wide, and $2 \mathrm{~m}$ deep. Figure 1 shows a schematic of the experimental setup and, the details of the two grids used are given in the appendix A. A Dantec Laser Doppler Anemometer (LDA) was used to measure two components of velocity, $u, v$, in the $x, y$, directions respectively. The LDA does not have a fixed sampling frequency, but the average sampling frequency was typically above $350 \mathrm{~Hz}$ providing high frequency velocity data to provide information on higher frequency turbulence structures.

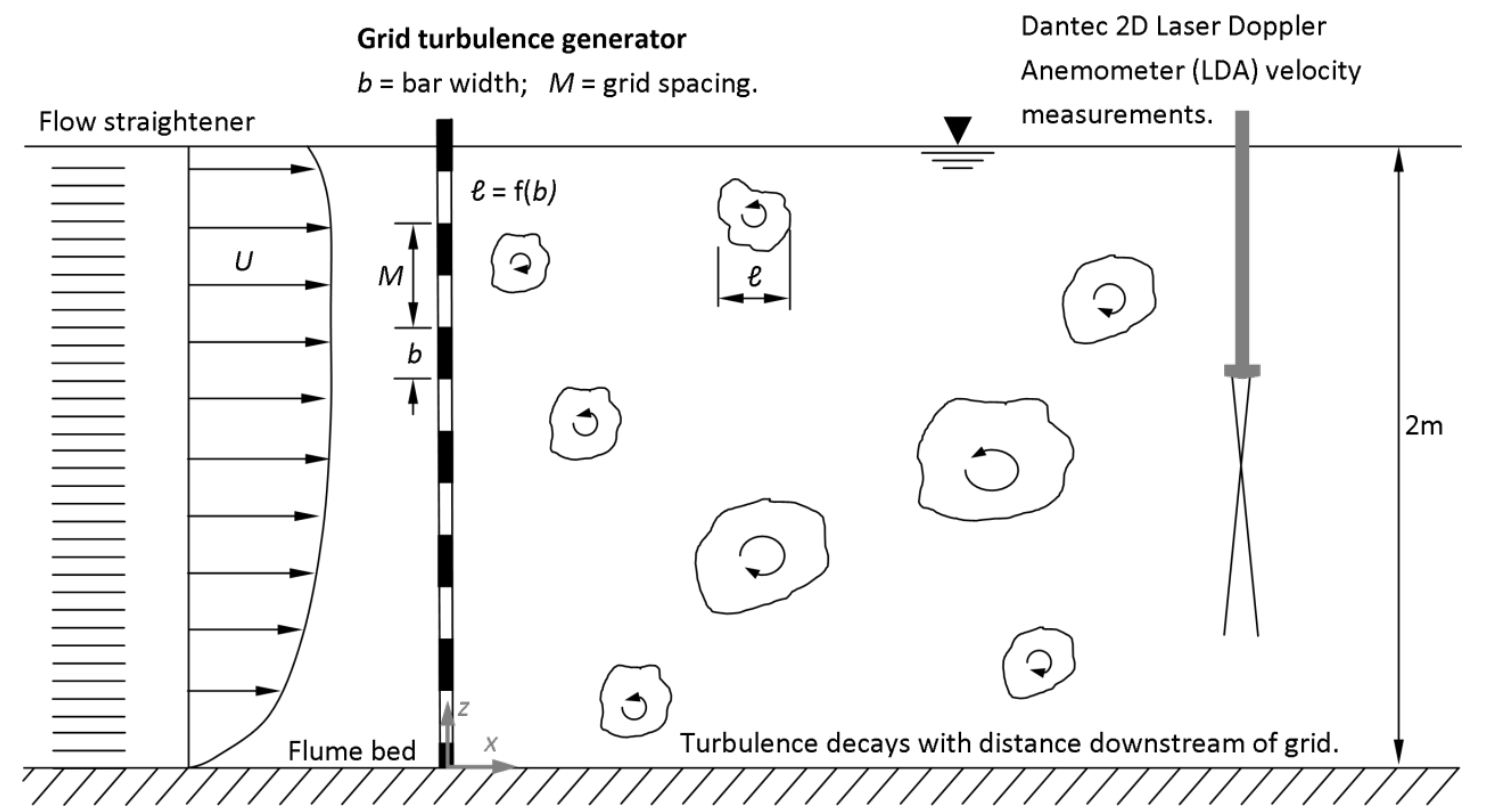

Figure 1 - Schematic showing static grid to generate turbulence with LDV and ADV for velocity measurements

An initial measurement using the LDA without the grids installed was used to assess the required sample period for each subsequent measurement based on the compromise between accuracy and available flume time. Flow mapping was then completed for the reference case without the grid installed. The flow map was measured across a $0.8 \mathrm{x} 0.8 \mathrm{~m}$ box located at the centre of the flume with measurements at every $0.2 \mathrm{~m}$, resulting in 25 measurements. This bounding box corresponds to the rotor diameter of a $1 / 20^{\text {th }}$ scale tidal turbine that will later be installed in these turbulent flows.

The small, $100 \mathrm{~mm}$ bar width, grid (see appendix A) was installed and measurements made on the flume centreline, progressing downstream to capture the turbulent energy decay. Flow maps were then completed at locations corresponding to approximately $15 \%, 10 \%$, and $5 \%$ turbulence intensity at $0.1 \mathrm{~m}$ resolution resulting in 81 measurements, plus a long 30 minute measurement at the centre to calculate higher order turbulence statistics.

The large, $400 \mathrm{~mm}$ bar width, grid (see appendix A) was installed and the process repeated. However, at the furthest downstream location the turbulence was still $17 \%$. Therefore flow maps were made at locations corresponding to $17 \%, 20 \%$, and $25 \%$ turbulence intensity at the same resolution for the small grid.

An instrumented $1 / 20^{\text {th }}$ scale 3 bladed horizontal axis tidal turbine was installed in the different turbulent flows to investigate the effects of turbulence on turbine performance and blade loading.

\section{Turbulence analysis}

While turbulence appears as chaotic and seemingly random fluctuations, they are in fact correlated in both time and space. It is not practically possible to obtain high resolution spatial measurements 
experimentally due to space requirements, instrument intrusion, and cost of multiple instruments. Instead, measurements are usually made at a single location over a time period. These velocity measurements may be decomposed into the mean, time-averaged velocity component and the fluctuating velocity component, as shown in equation 1.

$$
u(t)=U+u^{\prime}(t)
$$

Where $u(t)$ is the axial velocity component as a function of time $t ; U$ is the time-averaged axial velocity; and $u^{\prime}(t)$ is the velocity fluctuation from the mean as a function of time.

\subsection{Turbulence intensity}

The most commonly used parameter to describe turbulence in marine energy applications has been turbulence intensity, I. Turbulence intensity is the standard deviation, or root-mean-squared of velocity fluctuations normalised by the mean velocity and typically expressed as a percentage. For this work the one-dimensional turbulence intensity will be used and calculated using the axial velocity as shown in equation 2 .

$$
I=\frac{\sqrt{u^{\prime 2}}}{U}
$$

The turbulence intensity can be thought of as a measure of the strength, or overall turbulent energy level. Increasing the turbulence intensity increases the amount of turbulent energy within the flow. Behind a static grid the turbulence intensity decreases with distance downstream as shown in Figure 2(a). The turbulence decay is related to the size of the grid bars [19]. Figure 2(b) shows the turbulence intensities behind both the small and large grids fit to a similar decay rate when the downstream distance is normalised by the grid bar width. The decay of turbulence intensity is consistent with previous studies [10]. The turbulence intensities are higher for the large grid as the normalised downstream distance is less than for the small grid. This is due to the limitation imposed by the length of working section for a grid of this size.

\begin{tabular}{|c|c|}
\hline$x$ & small grid \\
\hline
\end{tabular}

(a)

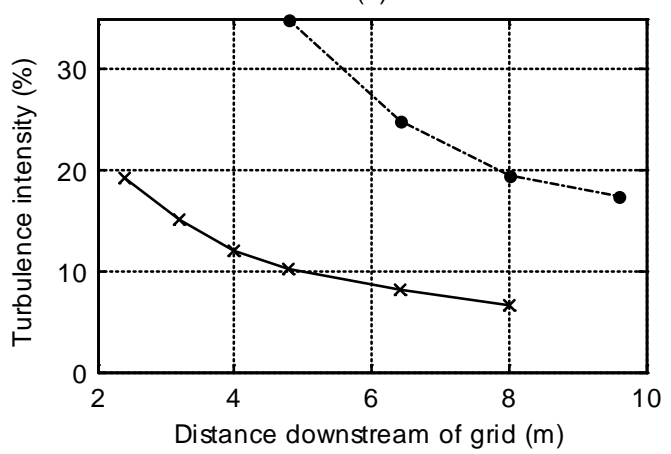

(b)

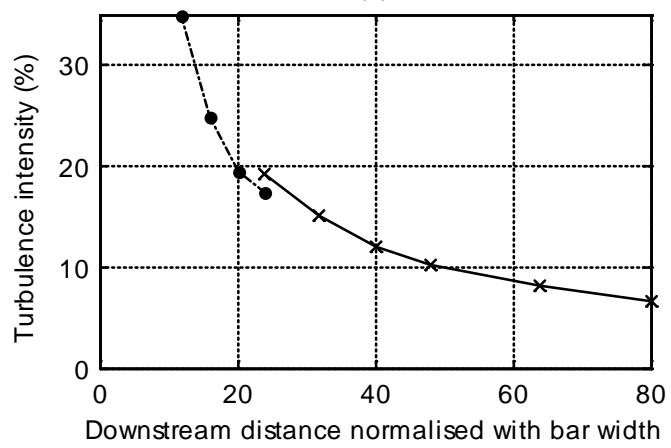

Figure 2 - Turbulence intensity behind the small and large grids. a) Distance downstream of grid in metres, b) Downstream distance normalised by grid bar width.

However, this parameter does not give any information on the spatial structure of turbulence. For example, it is possible to have 2 different flows with turbulence intensities of $10 \%$, but one has large scale, low frequency turbulent structures, and the other with small scale, high frequency structures. Previous investigations have found the integral length scale to be an important parameter resulting in significant variations in thrust and wake recovery[10], [11].

\subsection{Integral length scale}

The integral length scale can be thought of as the size of turbulent eddies that contain the largest proportion of turbulent energy; hence it is an averaged quantity due to the integration. The integral length scale is calculated in three steps. The first assumption is that the flow is statistically stationary. This assumes that the statistics calculated from $u(t)$ are invariant with time. This is a reasonable assumption given a sufficient sampling period. The autocovarience, $R(s)$, is calculated as:

$$
R(s)=\left\langle u^{\prime}(t) u^{\prime}(t+s)\right\rangle
$$


Where $s$ is the time lag and the angled brackets represent averaging. Normalising with $R(0)$ and integrating yields the integral time scale, $\tau$.

$$
\tau=\int_{0}^{T} \frac{R(s)}{R(0)} d s
$$

The normalised autocovarience, or autocorrelation function (ACF), has a value of 1 at a time lag of $s=0$. As the time lag increases the ACF reduces until it oscillates about zero. The integration is therefore typically performed between the limits of $s=0$ and the value of $\mathrm{s}$ where $\mathrm{ACF}=0$. However, in some cases the ACF may not oscillate about zero, or the zero crossing point may correspond to a very large time period that would equate to a length scale far larger than the geometric constraints of the flume. This would result in artificially high values of integral length scale and caused by noise in the measurements. The integral will therefore be performed up to $\mathrm{ACF}=T$, where $T$ is a threshold value corresponding to the maximum level of noise within the autocorrelation function [20].

The value of $T$ was calculated by performing a two point correlation between two velocity samples from the small and large grid and shown in Figure 3(a). The reason for this is to identify the noise within the autocorrelation. The two samples are uncorrelated, as from different experiments with different grids, and should return a correlation coefficient of zero. However, as seen in Figure 3(a) the maximum correlation coefficient is 0.038 . The reason for this correlation is not due to turbulence, as they are two independent experiments behind different grids. The cause is likely due to pump effects due to insufficient flow smoothing at the inlet. In calculating the integral length scale, the autocorrelation function was integrated up to this threshold value of $A C F=0.038$. Figure 3(b) shows the autocorrelation function for the small and large grid with the threshold value for integration indicated. It can be seen that the autocorrelation function is larger for the large grid than the small grid, as expected for a flow with larger scales of turbulence.
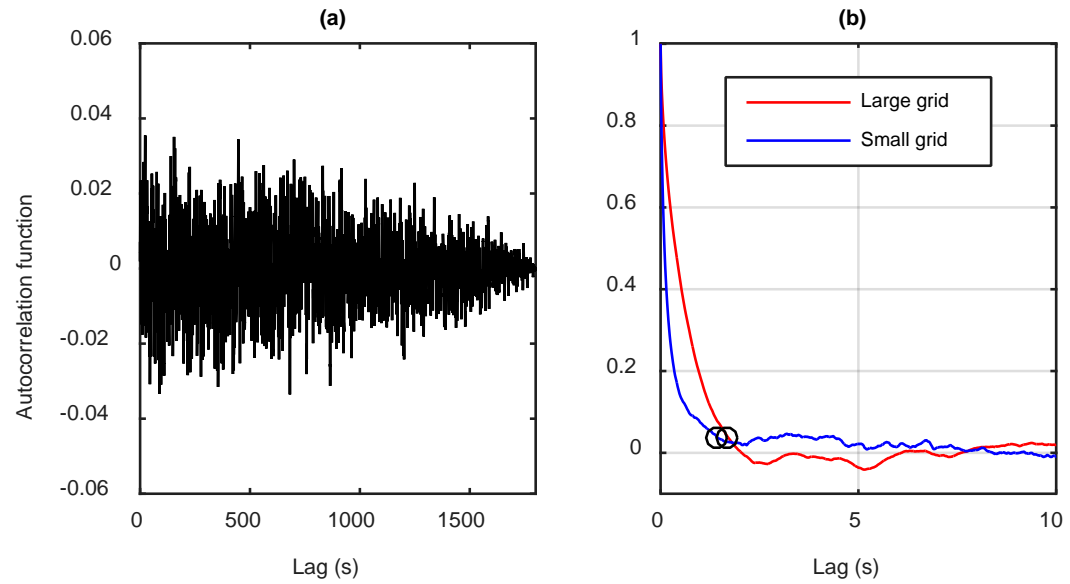

Figure 3 - (a) Two point correlation function between small and large grids. (b) Autocorrelation function of small and large grids, showing location integration is performed to.

Using Taylors hypothesis [19] the integral length scale, $\ell$, can be calculated as shown in equation 5. Taylor's hypothesis assumes that turbulent eddies travel with the mean flow as pure convection. This allows spatial derivatives in the axial direction to be approximated from the time derivative of a single point measurement. The assumption for this hypothesis is that $u^{\prime}<<U$.

$$
\ell=\tau . U
$$

Figure 4 shows the effect sample time on the integral length scale for the small and large grids with $\sim 15 \%$ and $\sim 17 \%$ turbulence intensity respectively. It can be seen that the integral length scale of the small grid is $0.18 \mathrm{~m}$ and $0.38 \mathrm{~m}$ for the large grid. 

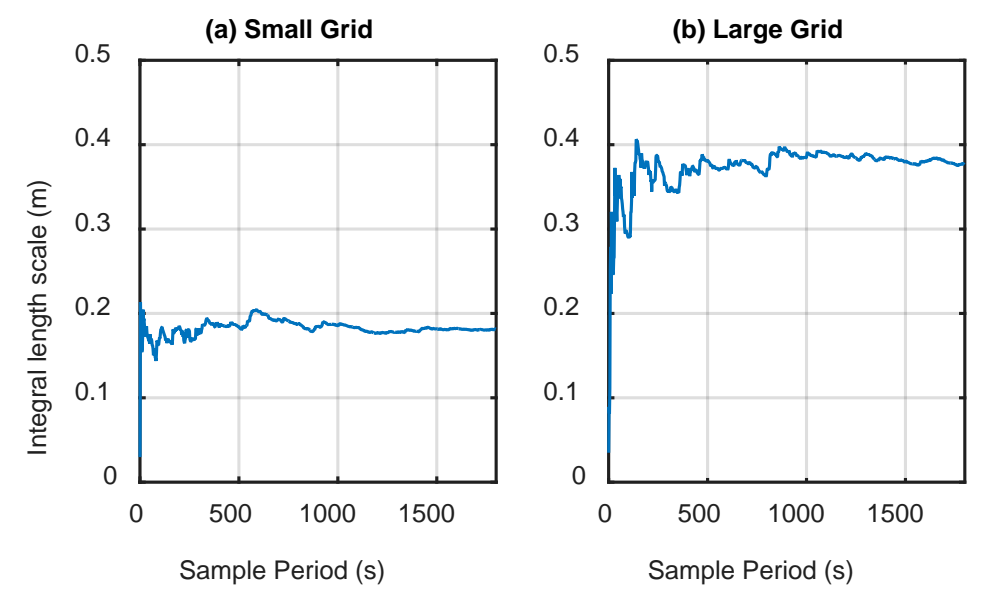

Figure 4 - Integral length scales for the (a) small and (b) large grids with increasing sample time.

\subsection{Sample period}

Before flow characterisation can be completed the sample period for each measurement needs to be decided. As, in most cases, this is a compromise between accuracy and time. A single 10 minute measurement was made at the centre of the flume using the LDA. The mean velocity, turbulence intensity, and integral length scale were then plotted with increasing sample time from $1 \mathrm{~s}$ to the full 10 minute sample as shown in Figure 5.

(a) Velocity



(b) Turbulence intensity

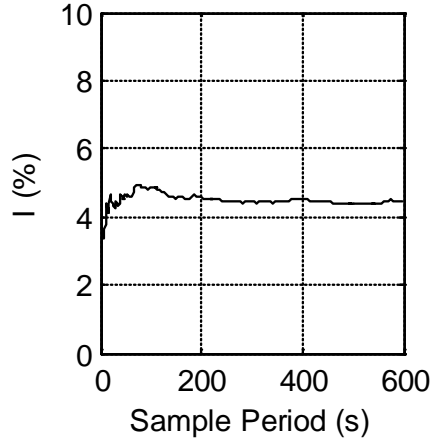

(c) Integral length scale

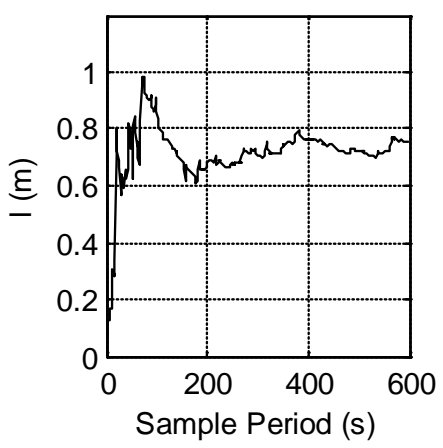

Figure 5 -Effect of sample time on mean velocity (a), turbulence intensity (b), and integral length scale (c).

It can be seen that the mean velocity converges for a sample of only 100 s, however the turbulence intensity stabilises at around 200s. The integral length scale shows greater variation with sample time and requires around $400 \mathrm{~s}$ before stabilising. It is expected that there would be greater variation as the integral length scale is a higher order statistic, and therefore the longer the sample time the better. However, there is a compromise with available time. It was decided to use a sample period of 200 s for the flow maps due to the large number of points as this gives sufficient accuracy for velocity and intensity. A further long measurement of 30 minutes was then taken at the centre of the flume to provide a long sample to give high confidence for the higher order statistics.

\subsection{Energy spectra and dominant length scales}

While the integral length scale gives an indication of the eddy size that contains the largest proportion of turbulent energy, it is also important to consider the full spectrum of eddy sizes and their contributions to the total turbulent energy. The energy spectral density provides this information and is the Fourier transform of the autocovarience, calculated using the following cosine transform.

$$
S(\omega)=\frac{2}{\pi} \int_{0}^{\infty} R(s) \cos (\omega s) d s
$$

$S(\omega)$ is an energy density, or energy per unit frequency, but is possible to convert to wavenumber, $x$, space by applying Taylor's hypothesis [19].

$$
\kappa=\frac{2 \pi}{L}=\frac{2 \pi \omega}{U}
$$


Where $L$ is the eddy length corresponding to a fluctuation frequency of $\omega$, with mean velocity $U$. The energy spectral density was calculated using the 'pwelch' function in MatLAB. Figure 6 shows the energy spectral density of the small and large grids. They have been converted into wavenumber space using the relation $x=2 \pi \omega / U$. It can be seen that increasing turbulence intensity increases the energy density. It can also be seen that the large grid contains greater energy than the small grid. For all cases behind the small and large grids the energy spectra collapse onto the $-5 / 3$ gradient, as predicted by Kolmogorov, showing the inertial subrange has been captured. However, this is not the case without a grid installed. A dip is observed in the energy spectra for the case without a grid for $1<x<100$. The cause is likely due to insufficient smoothing at the inlet to the flume allowing fluctuations from the pumps to propagate through the working section, as found for the autocorrelation in the previous section.
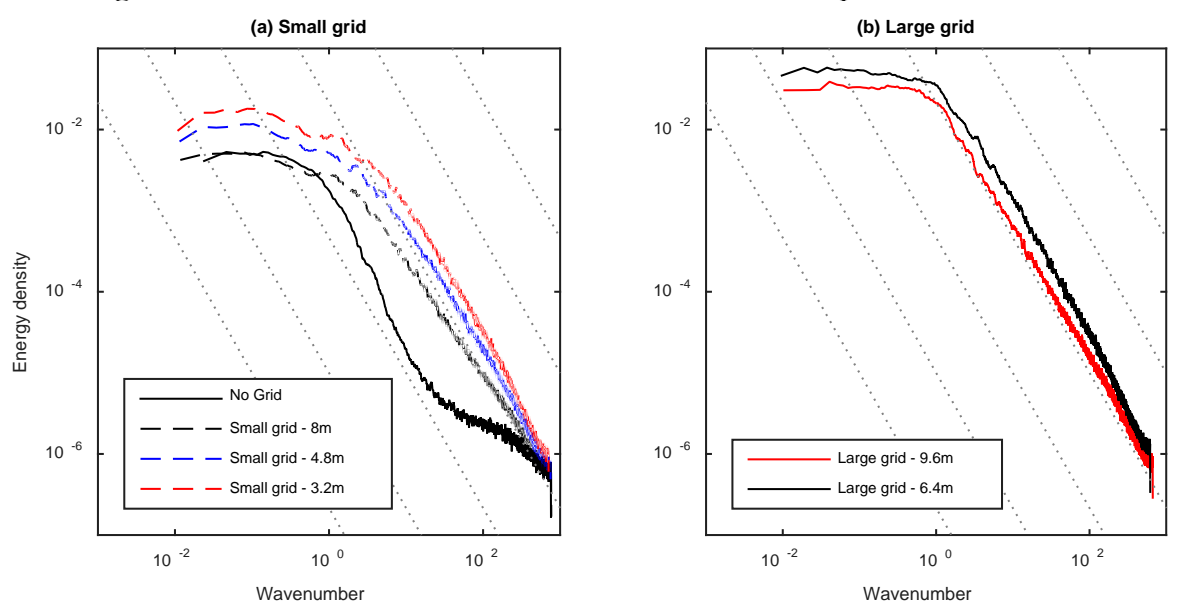

Figure 6 - Energy spectra for the different cases without a grid, and with small and large grids.

\subsubsection{Compensated energy spectra}

It is possible to plot the energy spectra in an alternative form to gain a greater understanding of the measurement quality. The compensated energy spectrum is defined as follows:

$$
S_{C}(\kappa \eta)=\frac{S(\kappa)}{\varepsilon^{2 / 3} \kappa^{-5 / 3}}
$$

Where $\varepsilon$ is the turbulence dissipation rate (see section 3.4.2), $\eta$ is the Kolmogorov micro scale and estimated using the following expression:

$$
\eta=\left(\frac{v^{3}}{\varepsilon}\right)^{1 / 4}
$$

Where $v$ is the kinematic viscosity. It should be noted that these are estimates as it is not possible to measure these parameters at sampling frequencies of $350 \mathrm{~Hz}$. Figure 7 shows the compensated energy spectra for the different cases. As before it can be seen that without the grid installed there is a dip at $x \eta=10^{-2}$. For all cases behind the two grids it can be seen that the compensated energy spectra tends to a constant value for $x \eta>10^{-3}$. This is further indication that the inertial subrange has been captured and the measurements are of high quality. Higher sampling frequency is still required to capture the bottleneck effect which would result in a peak in the compensated energy spectra for $x \eta>10^{-1}$ [19]. While this would be interesting to capture from a fundamental point of view, for the application to marine energy the lower frequency, larger scales of turbulence are likely to have the most significant effects on performance and fatigue loadings due to their higher energy content. 

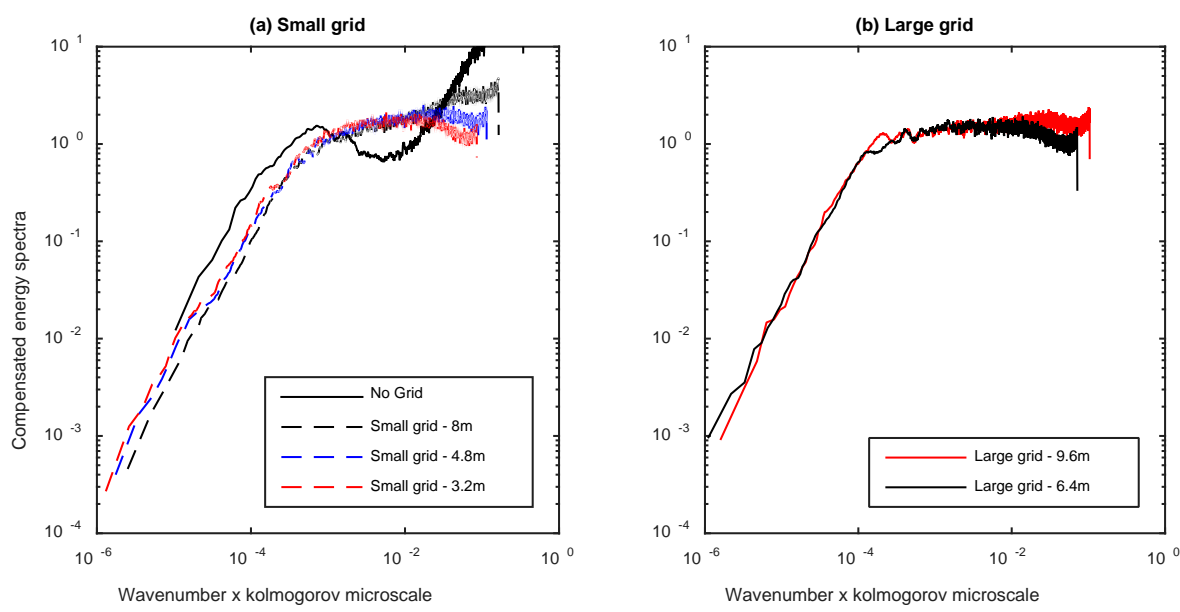

Figure 7 - Compensated energy spectra for the no grid and small grid (a), and the large grid (b).

\subsubsection{Pre-multiplied energy spectra and dominant length scales}

Another measure of turbulence scale is the dominant length scale which is the length scale corresponding to the turbulent eddies with the greatest energy. This sounds similar to the integral length scale, but they do differ. The integral length scale is an average quantity due to the integration, and may therefore differ from the dominant length scale. The dominant length scale can be better estimated from a pre-multiplied energy spectrum. The pre-multiplied energy spectrum is the energy density multiplied by the wavenumber.

$$
E(\kappa)=S(\kappa) \cdot \kappa
$$

The dominant length scale, $\ell_{d}=1 / \varkappa$, corresponds to the peak energy in the pre-multiplied energy spectrum as shown in Figure 8. It can be seen that a peak in turbulent energy occurs at a wavenumber of $x=1 \mathrm{~m}^{-1}$ for both the case with no grid, and the large grid, and $x=3.5 \mathrm{~m}^{-1}$ for the small grid. This corresponds to a dominant length scale of approximately $1 \mathrm{~m}$ for the case with no grid, $1 \mathrm{~m}$ for the large grid, and $0.29 \mathrm{~m}$ for the small grid. It is reassuring to note that the relative magnitudes of the integral length scales and dominant length scales between the small and large grids are consistent.

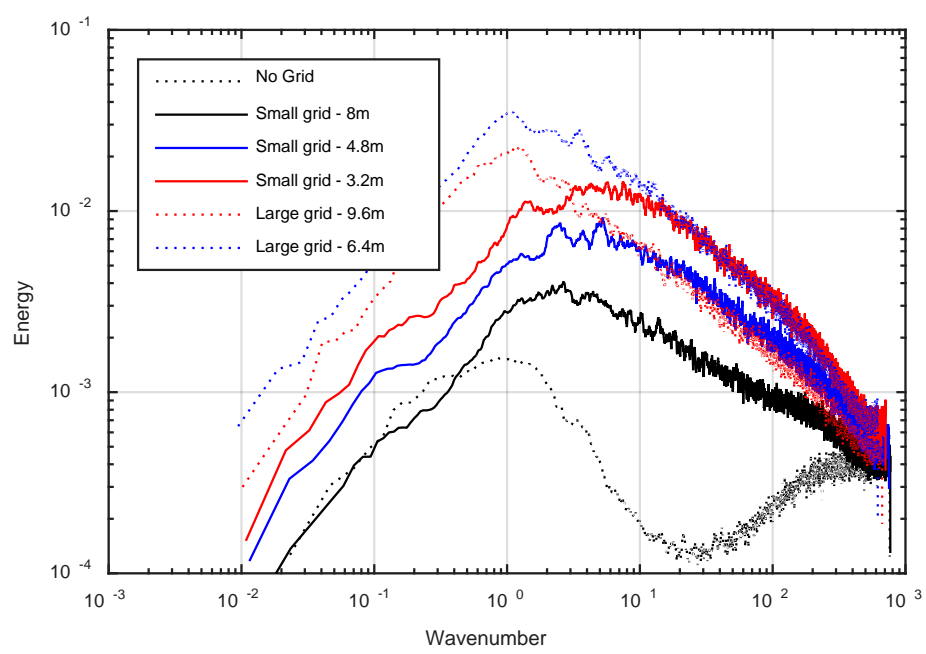

Figure 8-Pre-multiplied energy spectra for the different cases.

\subsubsection{Dissipation and Injection length scales}

The turbulence parameters discussed previously concern the energy and scales of turbulence.

However, it is also important to consider the rate at which turbulence is dissipated in the flow. Turbulent energy is transferred from the largest scales of turbulence down to the smallest scales of turbulence.

Below this, turbulent energy is dissipated as heat through viscous forces. The dissipation rate therefore provides information on the rate at which turbulent energy is cascaded from the largest to the smallest scales. The dissipation rate of turbulence, $\varepsilon$, is defined as: 


$$
\varepsilon=v\left\langle\frac{\partial u_{i}}{\partial x_{j}} \frac{\partial u_{i}}{\partial x_{j}}+\frac{\partial u_{i}}{\partial x_{j}} \frac{\partial u_{j}}{\partial x_{i}}\right\rangle
$$

Where $v$ is the kinematic viscosity, $\partial u_{i} / \partial x_{i}$ is the velocity gradient with subscript $i$ referring to the 3 coordinate dimensions. Obtaining sufficiently high resolution data to calculate these spatial derivatives is not easily achieved. The turbulent dissipation is therefore estimated by fitting Kolmogorov's $-5 / 3$ law to the energy spectrum, plotted in wavenumber space, as shown in equation 11.

$$
E(\kappa)=C \varepsilon^{2 / 3} \kappa^{-5 / 3}
$$

Where $x$ is the wavenumber and $C$ is the Kolmogorov's constant and assumed $C=1.5$.

Another measure of eddy size may now be defined as the injection length scale and calculated using equation 13.

$$
\ell_{i} \sim \frac{u^{\prime}}{\varepsilon}
$$

Assuming a constant of proportionality of unity, the size of eddies injected into the flow may be estimated [19].

Figure 9 shows the energy spectral density for the small and large grids. Lines of best fit have been generated using MatLAB in the form of equation 11 over the $-5 / 3$ gradient region.
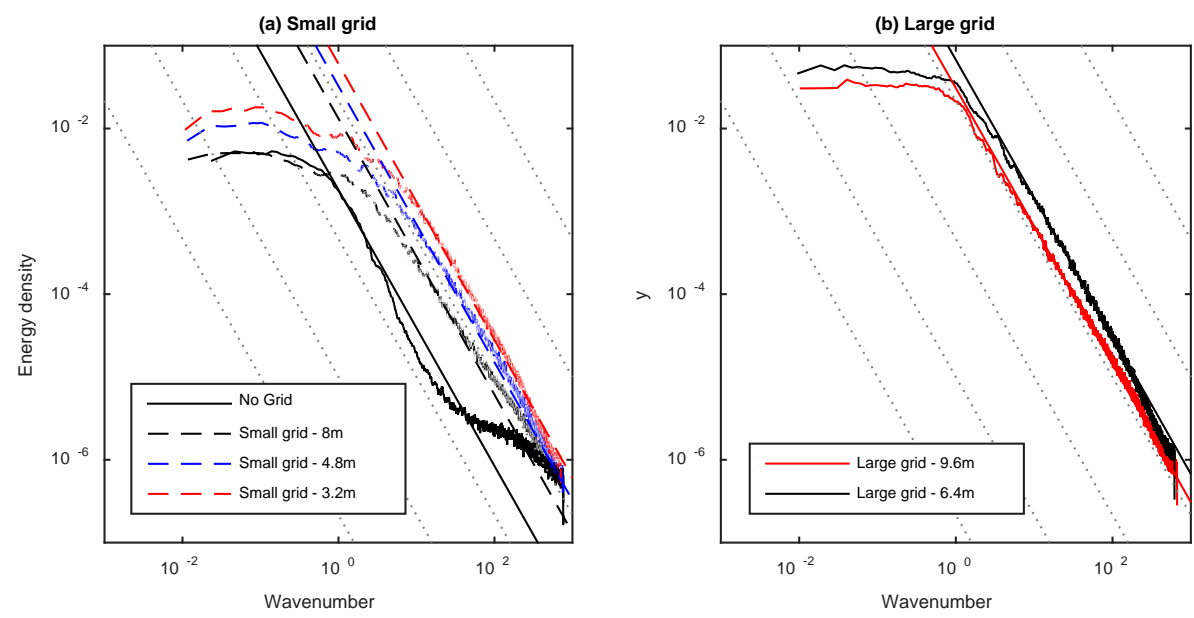

Figure 9 - Energy spectra for no grid and small grid (a) and the large grid (b) with fitted lines of $5 / 3$ gradient indicating the inertial subrange.

Table 1 shows the dissipation rate and injection length scale for the six cases shown in Figure 9. The dissipation rate is lowest without any grids installed. Behind each grid the dissipation rate reduces with increasing distance downstream. This results in the injection length scale increasing with downstream distance and in agreement with the integral length scales. The injection length scales are of similar magnitudes to the integral length scales found in section 3.3. Behind the small grid the injection length scales grow from $0.17 \mathrm{~m}$ to $0.21 \mathrm{~m}$, and behind the large grid they grow from $0.50 \mathrm{~m}$ to $0.65 \mathrm{~m}$. Without any grid the injection length scale was $1.02 \mathrm{~m}$.

Table 1 - Estimates of dissipation and injection length scale. $b$-grid bar width, $X$-dowstream distance from grid, $\varepsilon$-turbulence dissipation rate, $\ell_{\mathrm{i}}$-injection length scale.

\subsection{Isotropy of flow}

\begin{tabular}{|c|c|c|c|c|}
\hline & $b(m)$ & $X(m)$ & $\varepsilon\left(m^{2} / s^{3}\right)$ & $\ell_{i}(m)$ \\
\hline No grid & - & 2.9 & $4.22 \mathrm{E}-05$ & 1.02 \\
\hline small & 0.1 & 8 & $8.23 \mathrm{E}-04$ & 0.21 \\
\hline small & 0.1 & 4.8 & $3.20 \mathrm{E}-03$ & 0.17 \\
\hline small & 0.1 & 3.2 & $8.10 \mathrm{E}-03$ & 0.17 \\
\hline large & 0.4 & 9.6 & $2.90 \mathrm{E}-03$ & 0.65 \\
\hline large & 0.4 & 6.4 & $9.50 \mathrm{E}-03$ & 0.50 \\
\hline
\end{tabular}

Figure 10 shows the axial and transverse turbulence intensity. It can be seen that the flow is close to isotropic with the axial turbulence intensity approximately $10 \%$ greater than the transverse turbulence intensity behind the grids. This is consistent with wind tunnel studies on grid generated turbulence, for 
example [18]. Without a grid installed the ratio of axial to transverse turbulence intensity is over 2 , and the ratios summarised in Table 2. The Skewness and kurtosis were calculated and the average results shown

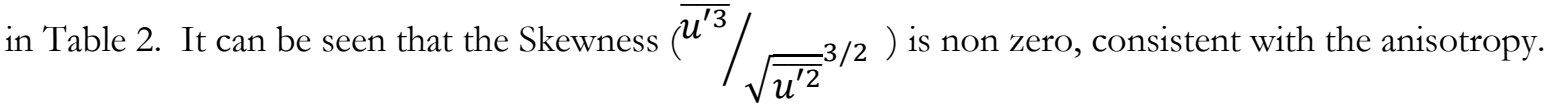
However, the kurtosis $\left.\overline{u^{\prime 4}} /{\overline{u^{\prime 2}}}^{2}\right)$ is close to 3 as found for a normal distribution.



Figure 10 - Axial and transverse turbulence intensity for centre point measurements.

Table 2 - Ratio of axial to traverse standard deviation, skewness (S) and kurtosis (K).

\begin{tabular}{|c|c|c|c|}
\hline & $\sqrt{\overline{u^{\prime 2}}}: \sqrt{\overline{v^{\prime 2}}}$ & Skewness & Kurtosis \\
\hline No Grid & 2.34 & -0.193 & 3.439 \\
\hline Small Grid & 1.12 & 0.191 & 3.021 \\
\hline large Grid & 1.10 & 0.308 & 3.098 \\
\hline
\end{tabular}

\subsection{Summary of centreline statistics}

This section has presented different turbulence statistics that have been calculated for the 30minute long centre point measurements for each case. It has been shown how the velocity measurements are of high quality and the inertial subrange of turbulence has been captured. Table 3 summarises the turbulence statistics for all cases. 
Table 3 - Summary of centre point statistics for each of the different cases.

\begin{tabular}{|c|c|c|c|c|c|c|c|c|c|c|c|c|}
\hline Grid & $\begin{array}{c}b \\
(m)\end{array}$ & $\begin{array}{c}X \\
(m)\end{array}$ & $\begin{array}{c}U \\
(\mathrm{~m} / \mathrm{s})\end{array}$ & $\begin{array}{c}u^{2} \\
(\mathrm{~m} / \mathrm{s})^{2}\end{array}$ & $\begin{array}{c}u^{3} \\
(\mathrm{~m} / \mathrm{s})^{3}\end{array}$ & $\begin{array}{c}I(\%) \\
(\mathrm{m})\end{array}$ & $\begin{array}{c}\ell_{d} \\
(\mathrm{~m})\end{array}$ & $\begin{array}{c}\ell_{i} \\
(\mathrm{~m})\end{array}$ & $\begin{array}{c}\varepsilon \\
\left(\mathrm{m}^{2} / \mathrm{s}^{3}\right)\end{array}$ & $S$ & $K$ \\
\hline No grid & - & 0 & 0.814 & 0.664 & 0.542 & 4.47 & 0.74 & 1.00 & 0.88 & $4.75 \mathrm{E}-05$ & -0.17 & 3.28 \\
\hline No grid & - & 2.9 & 0.808 & 0.655 & 0.531 & 4.55 & 0.73 & 1.00 & 1.02 & $4.22 \mathrm{E}-05$ & -0.19 & 3.36 \\
\hline No grid & - & 5.3 & 0.806 & 0.651 & 0.528 & 4.87 & 0.82 & 1.00 & 1.16 & $4.65 \mathrm{E}-05$ & -0.22 & 3.68 \\
\hline & & & & & & & & & & & & \\
\hline small & 0.1 & 8 & 0.818 & 0.672 & 0.555 & 7.01 & 0.25 & 0.29 & 0.21 & $8.23 \mathrm{E}-04$ & 0.12 & 3.03 \\
\hline small & 0.1 & 4.8 & 0.803 & 0.651 & 0.534 & 10.49 & 0.26 & 0.29 & 0.17 & $3.20 \mathrm{E}-03$ & 0.22 & 3.00 \\
\hline small & 0.1 & 3.2 & 0.760 & 0.591 & 0.469 & 14.84 & 0.18 & 0.29 & 0.17 & $8.10 \mathrm{E}-03$ & 0.23 & 3.04 \\
\hline & & & & & & & & & & & & \\
\hline large & 0.4 & 9.6 & 0.722 & 0.537 & 0.411 & 17.37 & 0.38 & 1.00 & 0.65 & $2.90 \mathrm{E}-03$ & 0.24 & 3.04 \\
\hline large & 0.4 & 8 & 0.702 & 0.511 & 0.386 & 19.34 & 0.32 & 1.00 & 0.53 & $4.50 \mathrm{E}-03$ & 0.34 & 3.16 \\
\hline large & 0.4 & 6.4 & 0.683 & 0.495 & 0.379 & 24.92 & 0.28 & 1.00 & 0.50 & $9.50 \mathrm{E}-03$ & 0.35 & 3.10 \\
\hline
\end{tabular}

In summary, Table 3 indicates that larger length scales and turbulence intensities were generated behind the large grid than the small grid. The turbulence intensity reduced with distance downstream, but there was insufficient length in the flume to achieve turbulence intensities less than $17 \%$ behind the large grid. The different measures of turbulence length scale showed similar trends behind the two grids and consistent with the changes in dissipation rates. As such the integral length scale will be used for flow mapping as is consistent with previous investigations and provides a measure of the average turbulent eddy size that contains the largest proportion of turbulent energy, and therefore likely to have the greatest impact on turbine performance and blade loads. Due to the shorter sample time used for flow mapping compared to the centre measurements, higher order statistics such as the integral length scale will likely show some variations.

\section{Flow mapping across turbine rotor area}

This section considers the full flow maps for 81 measurements across a $0.8 \times 0.8 \mathrm{~m}$ box at the flume centre, with $0.1 \mathrm{~m}$ resolution and $200 \mathrm{~s}$ sample time. The mapping presents the flow characterisation of the ambient flow with and without the grids installed. Flow maps are first presented to show the velocity, turbulence intensity and integral length scale at the central section of the flume. Following on from this, a turbine was installed in these flows and in all figures the turbine location is shown as a black circle.

\subsection{Flow characterisation}

\subsubsection{Ambient flow - no grid}

The purpose of this work was to generate flows with different turbulence characteristics that could then be used to investigate their effects on a marine current turbine. Before the grids were installed the ambient flow conditions in the flume were measured. Figure 11 shows the variation in axial velocity, turbulence intensity and integral length scale at the location where the grids would be installed. Minimal variation across the centre of the flume was observed with a mean velocity of $0.8 \mathrm{~m} / \mathrm{s}, \mathrm{I}=4.7 \%$, and $\ell=0.82 \mathrm{~m}$. Further measurements were made along the length of the flume at $2.9 \mathrm{~m}$ downstream, and $5.3 \mathrm{~m}$ as shown in Figure 12 and Figure 13 respectively. It can be seen that there is little variation along the length of the flume with a slight reduction in turbulence intensity from $4.7 \%$ to $4.5 \%$, and a slight reduction in integral length scale from 0.82 to $0.76 \mathrm{~m}$. 

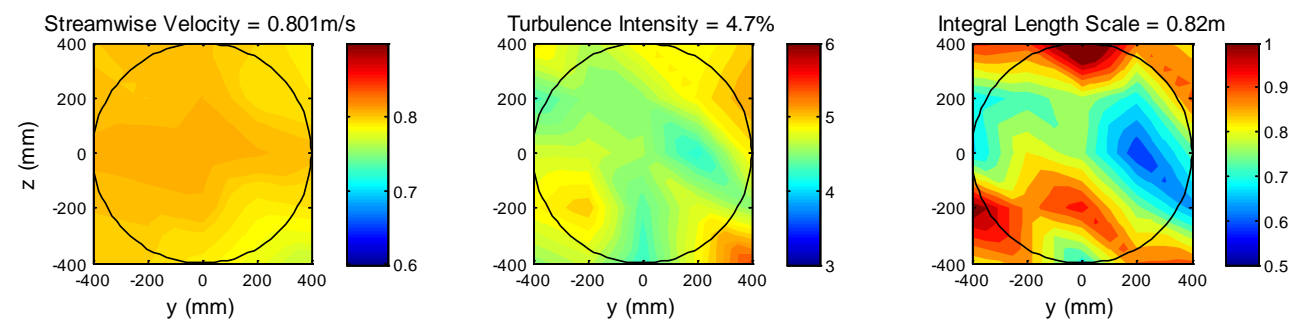

Figure 11 - Streamwise velocity, turbulence intensity, and integral lengths scale at the grid mounting location without the grid installed.
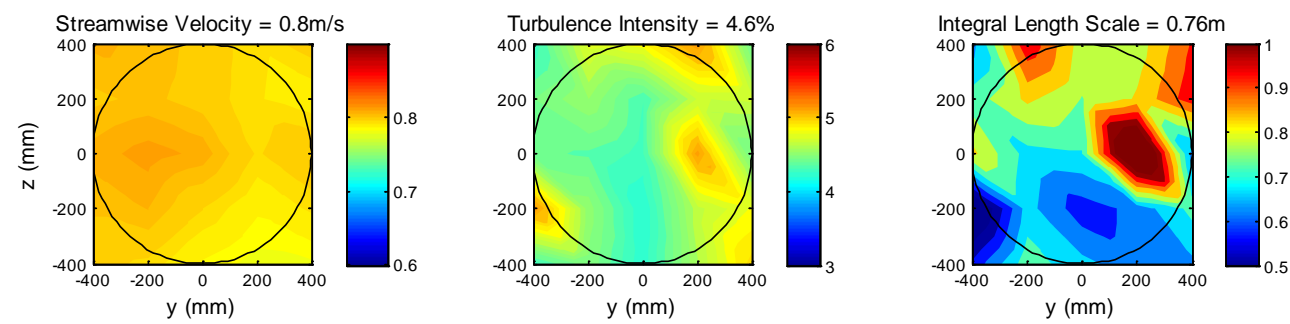

Figure 12 - Streamwise velocity, turbulence intensity, and integral lengths scale $2.9 \mathrm{~m}$ downstream of the grid mounting location without the grid installed.
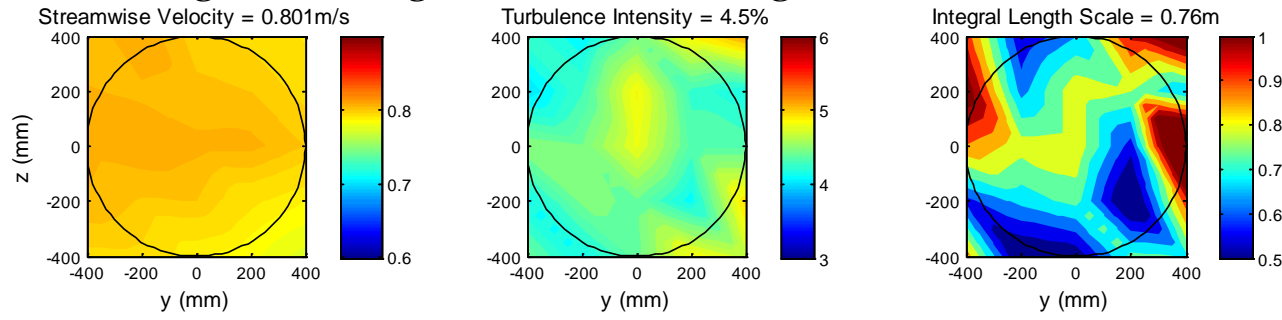

Figure 13 - Streamwise velocity, turbulence intensity, and integral lengths scale 5.3m downstream of the grid mounting location without the grid installed.

\subsubsection{Ambient flow - small grid}

The small grid was installed and measurements made at 3.2, 4.8, and $8 \mathrm{~m}$ downstream of the grid and the results shown in Figure 14, Figure 15, and Figure 16 respectively. It can be seen that a velocity shear gradient exists with higher velocities towards the upper region of the measurements. As before the mean velocity does not change significantly with downstream distance. The turbulence intensity decays with distance downstream from $14.3 \%$, to $10.2 \%$, to $6.8 \%$ at $3.2,4.8$, and $8 \mathrm{~m}$ respectively. Finally the integral length scales grow steadily from $0.15 \mathrm{~m}-0.22 \mathrm{~m}$ with distance downstream.
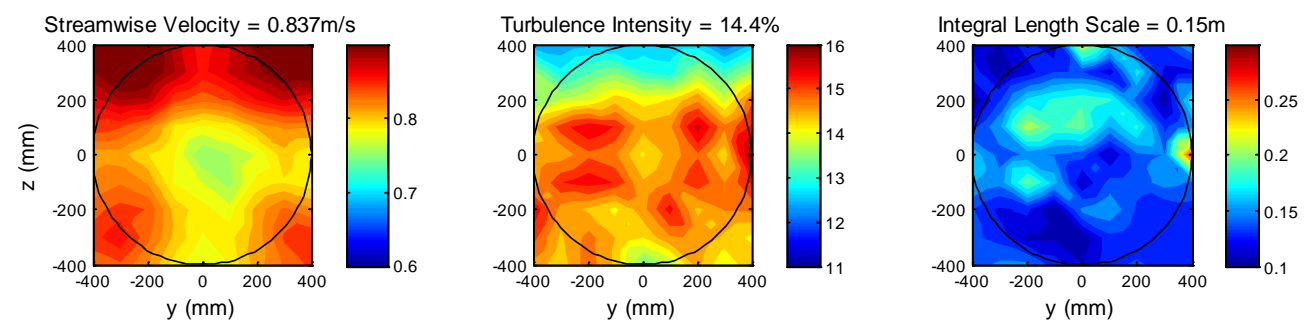

Figure 14 - Streamwise velocity, turbulence intensity, and integral lengths scale $3.2 \mathrm{~m}$ downstream of the small grid. 

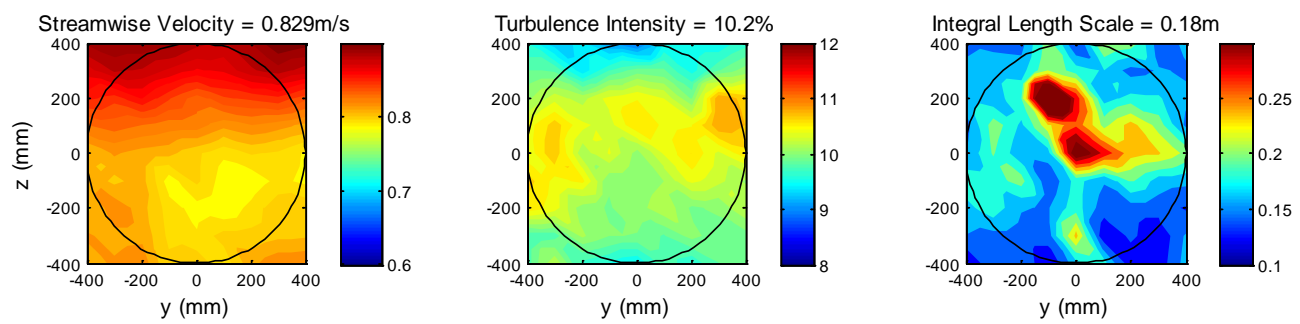

Figure 15 - Streamwise velocity, turbulence intensity, and integral lengths scale $4.8 \mathrm{~m}$ downstream of the small grid.
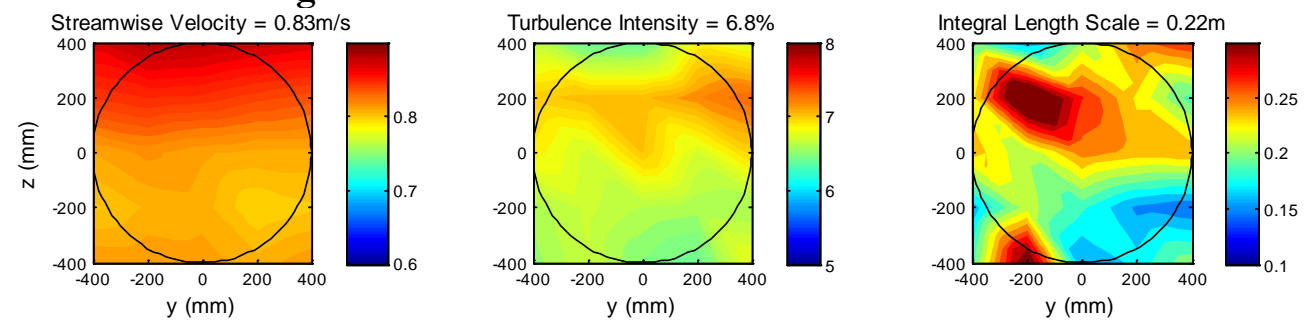

Figure 16 - Streamwise velocity, turbulence intensity, and integral lengths scale $8 \mathrm{~m}$ downstream of the small grid.

\subsubsection{Ambient flow - large grid}

The flow characterisation is shown in Figure 17, Figure 18, and Figure 19 at $6.4 \mathrm{~m}, 8 \mathrm{~m}$, and $9.6 \mathrm{~m}$ downstream of the grid respectively. It can be seen, in all cases, that the large grid has a lower mean velocity than the small grid, $0.72 \mathrm{~m} / \mathrm{s}$ compared to $0.82 \mathrm{~m} / \mathrm{s}$ for the small grid. This is possibly due to increased turbulence generation reducing the kinetic energy of the flow. It can also be seen that a greater shear gradient exists with higher axial velocities at the lower region of velocity measurements. This is opposite to what was observed for the small grid with higher velocities towards the surface. Larger surface deformations were observed behind the large grid compared to the small grid, and it is likely that the difference in location of accelerated flow is due to changes in the free surface deformation. Further tuning of the velocity profile would be possible by changing the distribution of grid bars, and requires further investigation.

The turbulence intensity decays from $25 \%$ at $6.4 \mathrm{~m}$ to $17.8 \%$ at $9.6 \mathrm{~m}$ downstream of the grid. Due to the geometry of the flume it was not possible to obtain lower turbulence intensities behind the large grid. As for the small grid the integral length scales grow with distance downstream of the grid from $0.28 \mathrm{~m}$ to $0.41 \mathrm{~m}$. It can be seen that the turbulence intensity and integral length scales are reasonably uniform across the measurement area. The variation in integral length scale maybe, in part, due to the restriction on sample time as discussed in section 3.2 and 3.3.
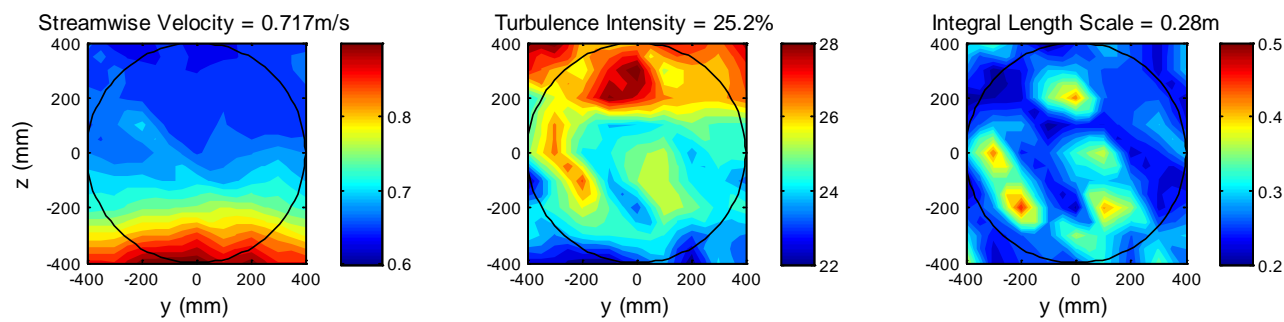

Figure 17 - Streamwise velocity, turbulence intensity, and integral lengths scale $6.4 \mathrm{~m}$ downstream of the large grid. 

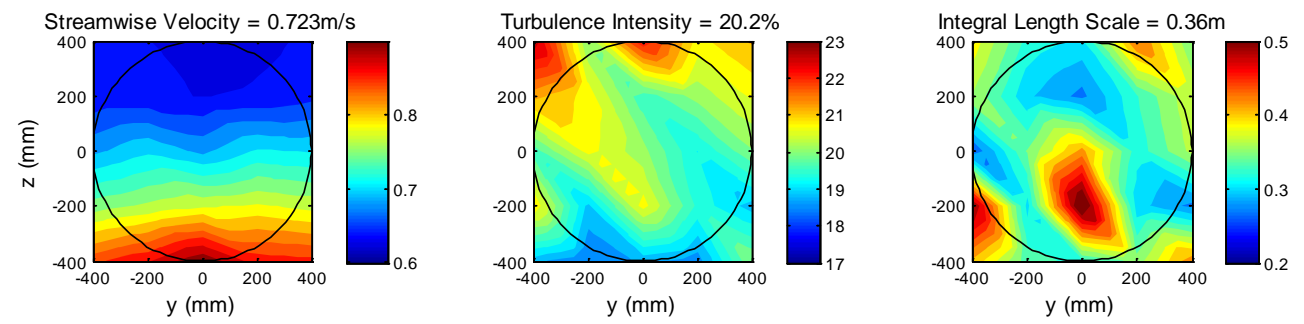

Figure 18 - Streamwise velocity, turbulence intensity, and integral lengths scale $8 \mathrm{~m}$ downstream of the large grid.
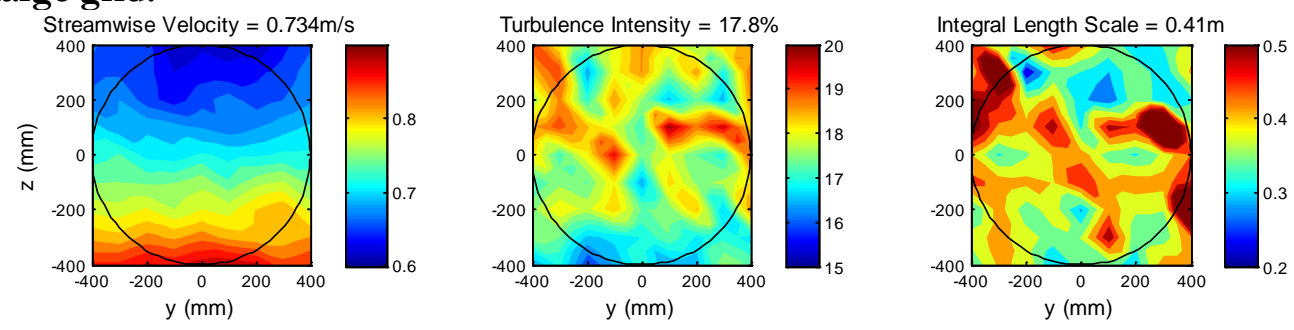

Figure 19 - Streamwise velocity, turbulence intensity, and integral lengths scale $9.6 \mathrm{~m}$ downstream of the large grid.

\subsection{Discussion and Summary of Mapping Observations}

The flow characterisation of the flume without the grid installed showed that the axial velocity, turbulence intensity, and integral length scale are reasonably uniform across the centre of the flume with mean values of $\mathrm{U}=0.8 \mathrm{~m} / \mathrm{s}, \mathrm{I}=4.6 \%, \ell=0.76 \mathrm{~m}$. This suggests that they are outside of the boundary layer and can be considered as free-stream conditions.

Flow characterisation behind the small grid showed the turbulence intensity decayed from $14.3 \%$ to $6.8 \%$ with integral length scales growing from $0.15 \mathrm{~m}-0.22 \mathrm{~m}$. While the turbulence intensity and integral length scale showed reasonably uniform profiles, a shear gradient was present with higher velocities for $\mathrm{z}>200 \mathrm{~mm}$. The reason for this shear gradient is unknown and was not observed in previous experiments using grid generated turbulence in flumes [10]. However, the overall variation in velocity is $\sim 5 \%$ and therefore relatively small.

As with the small grid, the large grid generated reasonably uniform profiles of turbulence intensity and integral length scales. The turbulence intensity decayed from $25.2 \%$ to $17.8 \%$ while the integral length scales grew from $0.28 \mathrm{~m}$ to $0.41 \mathrm{~m}$. However, a larger shear gradient of $\sim 30 \%$ was observed with the higher velocities towards the bottom. The cause of this is unknown but likely due to free surface effects.

This seminal experimental campaign and the generated results show how grids may be used to generate flows with different turbulence characteristics within flumes. Using different grid bar widths and downstream distances from the grid the length scales and turbulence intensity may be changed. Table 4 shows a summary of the turbulence characteristics for 6 cases that the turbine will be operated in.

The range of turbulence conditions covers the expected turbulence intensities at tidal sites of approximately $10-15 \%$ [8], [9], although the length scales will likely be smaller due to the restrictions imposed by the flume size. However, it is not our intention to recreate the conditions at a specific tidal site, but to generate a range of turbulence intensities and length scales in which the turbine can operate to assess how they affect its performance and blade loads. Further work is ongoing to assess site specific turbulence conditions. The next section presents the results from the turbine.

Table 4 - Summary of area average turbulence characteristics.

\begin{tabular}{cccccccc}
\hline Case & \multirow{2}{*}{ Grid } & $\begin{array}{c}\text { Downstream } \\
\text { distance }(\mathbf{m})\end{array}$ & $\begin{array}{c}\boldsymbol{U} \\
(\mathbf{m} / \boldsymbol{s})\end{array}$ & $\overline{\left\langle\boldsymbol{u}^{\prime \mathbf{2}}\right\rangle}$ & $\overline{\left\langle\boldsymbol{u}^{\prime \mathbf{3}}\right\rangle}$ & $\boldsymbol{I}(\boldsymbol{\%})$ & $\boldsymbol{\ell}(\mathbf{m})$ \\
\hline 1 & No grid & - & 0.800 & 0.6442 & 0.5187 & 4.6 & 0.76 \\
2 & Small grid & 3.2 & 0.839 & 0.6931 & 0.5968 & 14.3 & 0.15 \\
3 & Small grid & 4.8 & 0.830 & 0.6826 & 0.5737 & 10.2 & 0.18 \\
4 & Small grid & 8 & 0.830 & 0.6856 & 0.5723 & 6.8 & 0.22 \\
5 & Large grid & 6.4 & 0.720 & 0.5356 & 0.4328 & 25.2 & 0.28 \\
6 & Large grid & 9.6 & 0.736 & 0.5515 & 0.4331 & 17.8 & 0.41 \\
\hline
\end{tabular}




\section{Turbine performance and blade loadings}

This section presents the use of grid generated turbulent flows to investigate the effects of turbulence on the performance of a tidal turbine. In the previous sections we have shown how static grids can be used to generate turbulent flows in a flume with different characteristics. The driving force behind this method and the work is its application to the tidal energy industry. As discussed earlier, the turbulence characteristics in a tidal flow are site specific. For example, a site with a jagged rocky sea bed will produce different turbulence characteristics to a smooth sandy seabed. It is therefore important to understand how a turbines performance and loadings may be affected when operating in flows with different turbulence intensities and length scales. In this study grid generated turbulence is used as it provides control to change the turbulence intensities and length scales within the flume, as discussed in the previous section. The flow is also approximately uniform and isotropic which allows the specific effects of turbulence to be investigated.

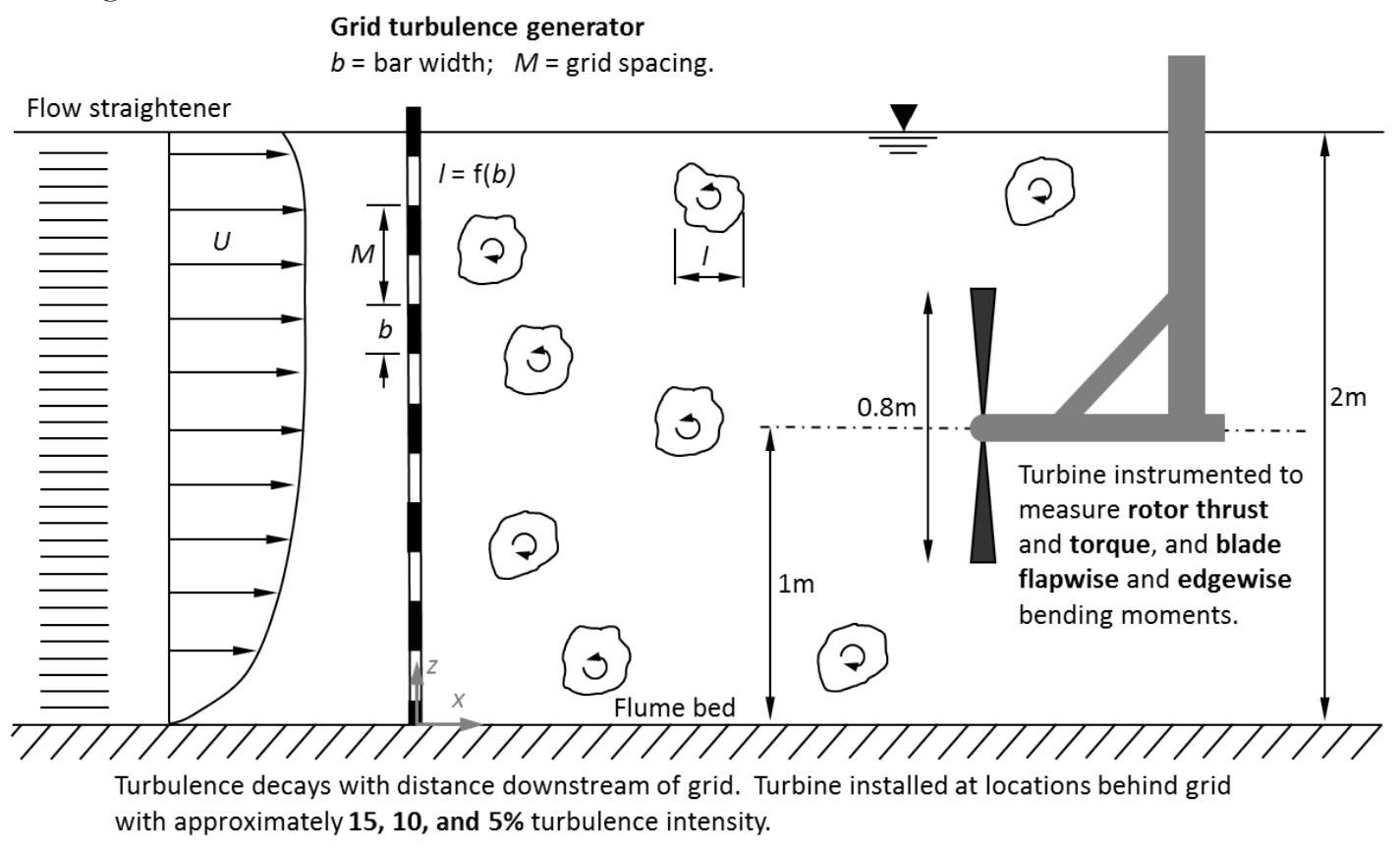

Figure 20 - Schematic of experimental method with turbine installed in a turbulent flow.

A sequence of experiments were conducted on a $0.8 \mathrm{~m}$ diameter three bladed horizontal axis tidal turbine which was installed downstream of the turbulence generating grids as shown in Figure 20. The turbulence characteristics of the 6 different test cases are summarised in Table 4. The turbine was designed and built by the University of Southampton and uses a custom designed thrust torque dynamometer that runs wet to measure the thrust and torque at the rotor. One blade is instrumented to measure the flapwise and edgewise blade root bending moments, as defined in Figure 21. Further details of the turbine can be found in [21]. The turbine was controlled using a fast response electronic load to maintain constant rpm. 


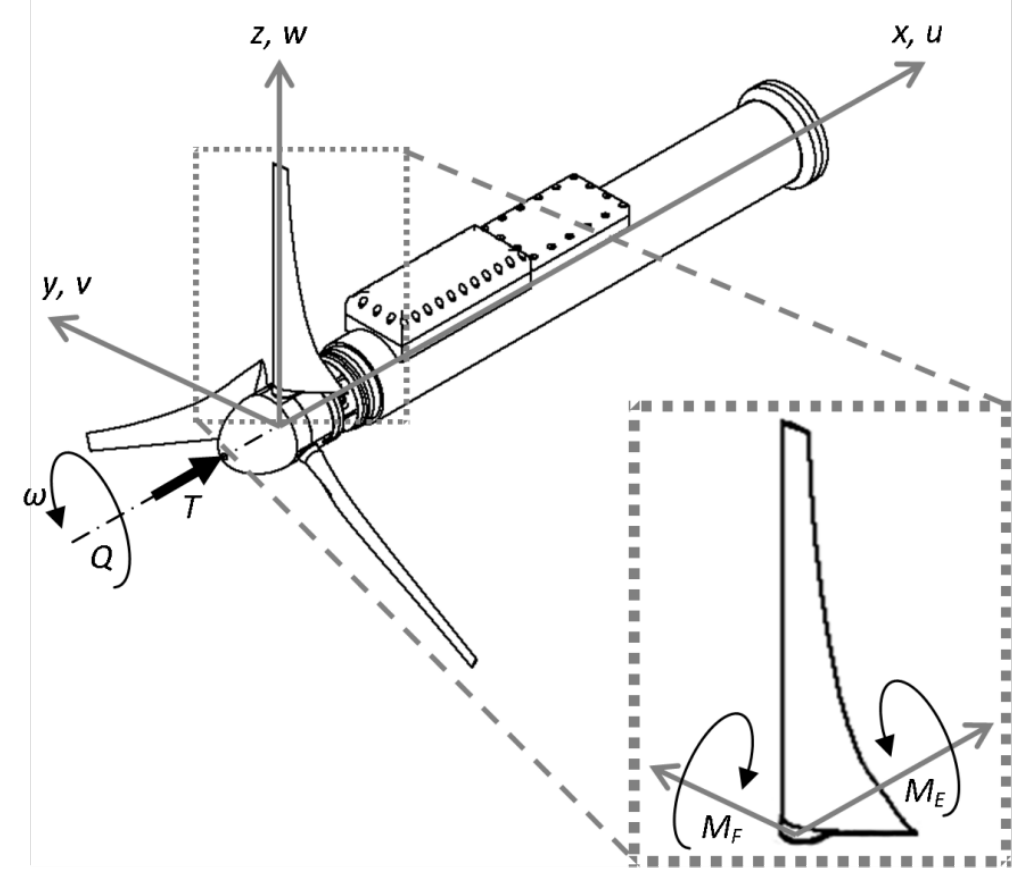

Figure 21 - Turbine coordinate system with flapwise, $M_{F}$, and edgewise, $M_{E}$, blade root bending moments.

The turbine thrust and power are presented as non-dimensional coefficients.

$$
C_{T}=\frac{T}{\frac{1}{2} \rho \chi_{i}^{2} A}
$$

Where $C_{T}$ is the thrust coefficient, $T$ is the rotor thrust, $\rho$ is density, $A$ is the rotor area and $\chi_{i}{ }^{2}$ is the ambient velocity squared.

$$
C_{P}=\frac{P}{\frac{1}{2} \rho \chi_{i}{ }^{3} A}=\frac{Q \omega}{\frac{1}{2} \rho \chi_{i}{ }^{3 A}}
$$

Where $C_{P}$ is the power coefficient, $P$ is the rotor power, $Q$ is the rotor torque, $\omega$ is the rotational speed, and $\chi_{i}{ }^{3}$ is the ambient velocity cubed. Three different estimates of the ambient velocity are considered. The first estimate uses the time averaged velocity at hub height.

$$
\chi_{1}=\bar{u}_{H H}
$$

Where the over bar represents time averaging, and $u_{H H}$ is the velocity at hub height (the centre of the channel). The second method spatially averages the velocities over the rotor area:

$$
\chi_{2}=\langle\bar{u}\rangle_{A}
$$

Where \langle\rangle$_{A}$ represents averaging over the rotor area. The final estimate of ambient velocity performs the squaring, or cubing before time averaging.

$$
\chi_{3}{ }^{n}=\left\langle\overline{u^{n}}\right\rangle_{A}
$$

Where the superscript, $n$, is power 2 for the thrust coefficient and power 3 for the power coefficient.

The flapwise and edgewise blade root bending moment coefficients are defined as:

$$
\begin{aligned}
C_{M_{F}} & =\frac{M_{F}}{\frac{1}{2} \rho \chi_{i}{ }^{2} A R} \\
C_{M_{E}} & =\frac{M_{E}}{\frac{1}{2} \rho \chi_{i}{ }^{2} A R}
\end{aligned}
$$

Where $C_{M_{F}}$ is the flapwise blade root bending moment coefficient and $C_{M_{E}}$ is the edgewise blade root bending moment coefficient, as defined in Figure 21.

\subsection{Calibration and uncertainty analysis}

The turbine thrust/torque dynamometer was calibrated using standard weights of $1 \pm 0.01 \mathrm{~kg}$ and the blade root bending moment calibrated using standard weights of $0.5 \pm 0.005 \mathrm{~kg}$ hung at $0.3 \pm 0.0005 \mathrm{~m}$ from the blade root. The applied force was calculated using $F=m g$, where $g$ is the gravitational constant $g=9.81 \pm 0.001 \mathrm{~m} / \mathrm{s}^{2}$. The calibration resulted in linear correlations with coefficients of determination of 
0.9998 or better, as shown in Figure 22(a) for the edgewise blade root bending moment. Table 5 shows the results from an uncertainty analysis performed using the method described in [22], and discussed in [15], [23]. It can be seen that in all cases the total uncertainty is low, and is less than $1.5 \%$ of the mean. Figure 22(a) shows uncertainty bounds for the edgewise blade root bending moment, note these are only visible on the zoomed in scale.

Table 5 - Uncertainty in turbine load measurements.

\begin{tabular}{|c|c|c|c|c|}
\hline & \multicolumn{2}{|c|}{ Rotor } & \multicolumn{2}{c|}{ Blade root bending moments } \\
\hline & $\begin{array}{c}\text { Thrust } \\
(\mathrm{N})\end{array}$ & $\begin{array}{c}\text { Torque } \\
(\mathrm{Nm})\end{array}$ & $\begin{array}{c}\text { Edgewise } \\
(\mathrm{Nm})\end{array}$ & $\begin{array}{c}\text { Flapwise } \\
(\mathrm{Nm})\end{array}$ \\
\hline Precision uncertainty & 0.4540 & 0.0307 & 0.0363 & 0.0219 \\
\hline Bias uncertainty & 0.7098 & 0.0788 & 0.0339 & 0.0265 \\
\hline Total uncertainty & 0.8426 & 0.0846 & 0.0497 & 0.0344 \\
\hline Percentage of mean & $1.19 \%$ & $1.08 \%$ & $1.48 \%$ & $1.31 \%$ \\
\hline
\end{tabular}

The error associated with sample time has also being estimated. As the edgewise blade root bending moment showed the greatest variation and error, this measurement would be most sensitive to the sample time. Taking the highest turbulence case behind the large grid as the worst case scenario, the turbine was installed and a 10 minute sample recorded. Figure 22(b) shows the error in the mean edgewise blade root bending moment with increasing sample time from 5-600s. It can be seen that the mean and standard deviation converge with an error of less than $1 \%$ for sample times greater than 200 s. A sample time of 300 s was chosen for the turbine measurements as being an acceptable compromise between available flume time and accuracy.

a)

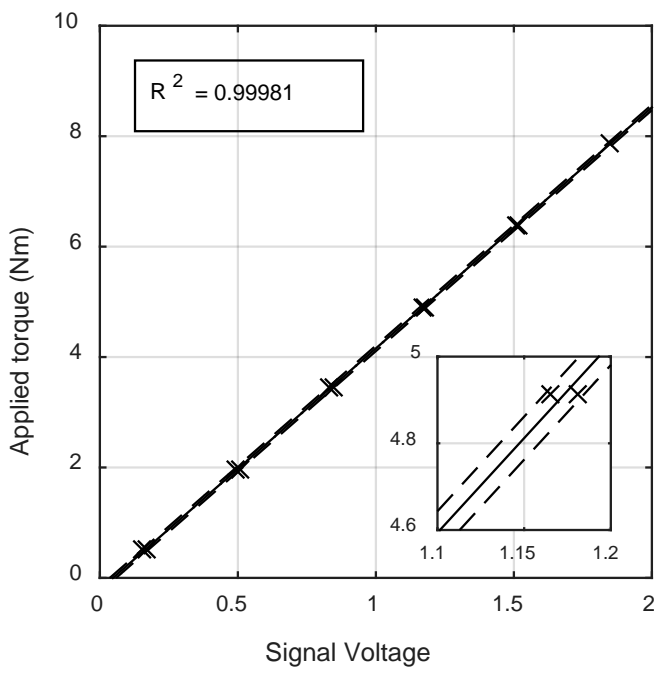

b)

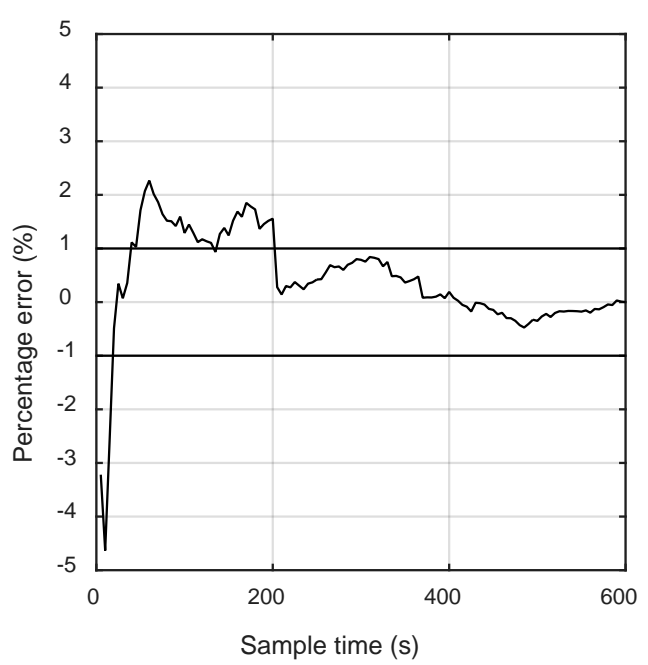

Figure 22 - Edgewise blade root bending moment calibration and percentage error with sample time.

\subsection{Turbine power and thrust coefficients}

The turbine was operated in the different flows over a range of different rotational speeds. Figure 23 shows the thrust and power coefficients for the six different cases. Figure 23(a) shows the thrust and power coefficients using the centre point measurement as an estimate of ambient velocity. It can be seen that a large variation in turbine performance exists with $0.4<C_{P}<0.6$. However, this is likely to be skewed due to the velocity shear observed in the velocity flow maps behind the grids and would be very optimistic considering the Betz limit is 0.59[24]. This finding is consistent with previous investigations using sheared velocity profiles [25]. Figure 23(b) shows the thrust and power coefficients using the spatial average over the rotor area as the estimate of ambient velocity to take into account any effects due to 
velocity shear. The turbine performance appears to collapse for the small and large grids. However, in the highly turbulent cases behind the large grid the turbine power coefficient is still almost 0.55 . Figure 23(c) shows the turbine thrust and power coefficients using an estimate of ambient velocity where the velocity is squared, or cubed, before temporal and spatial averaging to take into account the dynamic nature of the flow and provide a true RMS value. It can be seen that the coefficients further collapse with an overall range in peak power coefficient of $0.38<C_{P}<0.46$. For a given grid, or length scale, it can be seen that increasing the turbulence intensity reduces the power coefficient. Increasing the length scale shows an increase in power coefficient.

\begin{tabular}{|c|c|c|c|c|c|c|c|c|c|c|c|}
\hline$\times$ & $\begin{array}{l}\text { Case } 1 \\
I=4.6 \% \\
\ell=0.76 \mathrm{~m}\end{array}$ & + & $\begin{array}{l}\text { Case } 2 \\
I=14.3 \% \\
\ell=0.15 \mathrm{~m}\end{array}$ & * & $\begin{array}{l}\text { Case } 3 \\
I=10.2 \% \\
\ell=0.18 \mathrm{~m}\end{array}$ & • & $\begin{array}{l}\text { Case } 4 \\
I=6.8 \% \\
\ell=0.22 \mathrm{~m}\end{array}$ & $\nabla$ & $\begin{array}{l}\text { Case } 5 \\
I=25.2 \% \\
\ell=0.28 \mathrm{~m}\end{array}$ & 0 & $\begin{array}{l}\text { Case } 6 \\
I=17.8 \% ; \\
\ell=0.41 \mathrm{~m}\end{array}$ \\
\hline
\end{tabular}
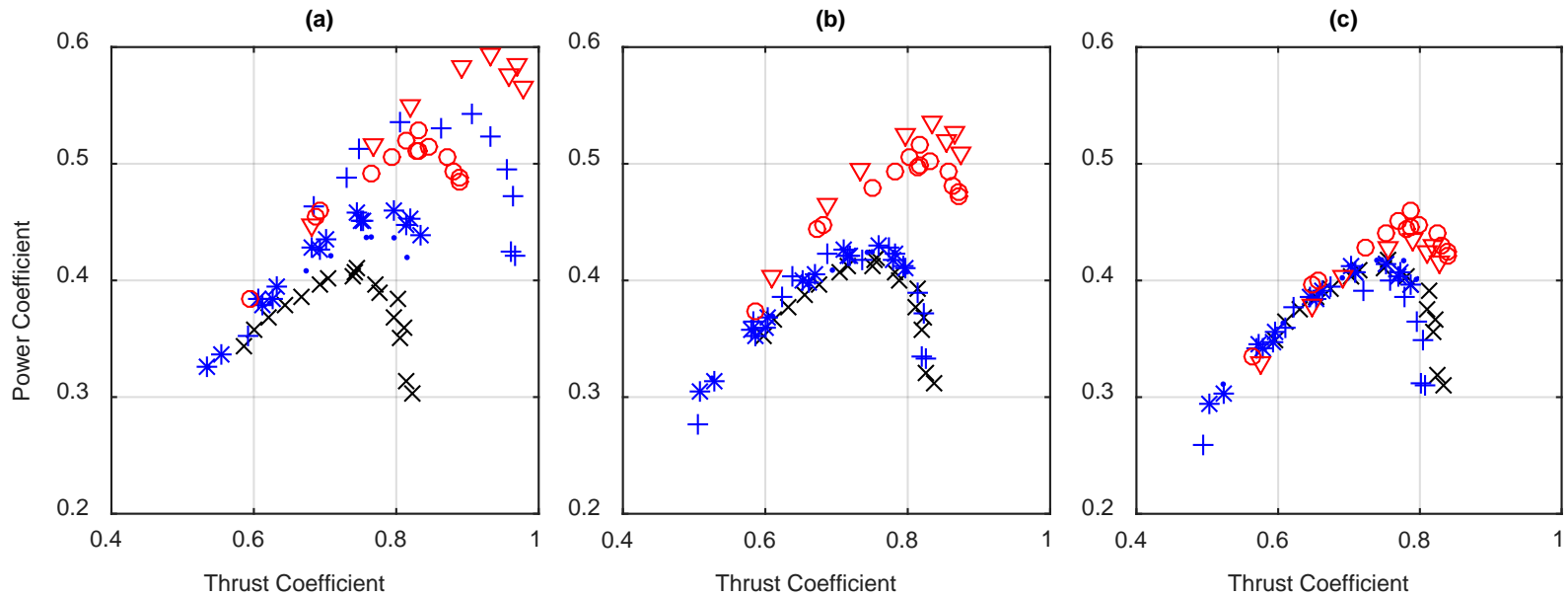

Figure 23 - Turbine thrust and power coefficients for a turbine operating in the turbulent flows using different normalisation velocities: a) average velocity squared/cubed; b) Area averaged velocity squared/cubed; c) Velocity squared/cubed then area averaged. Black - no grid, blue small grid, red - large grid.

Figure 23 shows significant variation in power and thrust coefficient for different flow conditions and estimates of ambient velocity. It is interesting to note, that given a flow with sufficiently strong fluctuations in velocity the Betz limit may be exceeded. It is therefore important that the squaring, or cubing, of velocity should be performed prior to temporal and spatial averaging.

\subsubsection{Turbulence intensity effects}

To consider the effects of turbulence intensity case 2, (small grid, $3.2 \mathrm{~m}$ distance) and case 4 (small grid, $8 \mathrm{~m}$ distance) are compared with turbulence intensities of $6.8 \%$ and $14.3 \%$ respectively and integral length scales of $0.22 \mathrm{~m}$ and $0.15 \mathrm{~m}$ respectively. It can be seen in Figure 24 that increasing the turbulence intensity reduces the power and thrust coefficients of the turbine. A reduction in power coefficient of around $10 \%$ is observed for an increase in turbulence intensity from 6.8 to $14.3 \%$. This finding is consistent with previous findings with different turbulence intensities [14]. 


- Case $4: I=6.8 \% ; \ell=0.22 \mathrm{~m} \quad+\quad$ Case $2: I=14.3 \% ; \ell=0.15 \mathrm{~m}$



Figure 24 - Power and thrust coefficients for cases 4 (small grid, 8m distance) and 2 (small grid, $3.2 \mathrm{~m}$ distance) with turbulence intensities of $6.6 \%$ and $15.1 \%$ respectively.

\subsubsection{Length scale effects}

To consider the effects of integral length scale case 2 (small grid, $3.2 \mathrm{~m}$ distance) and case 6 (large grid, $9.6 \mathrm{~m}$ distance) are compared with turbulence intensities of $14.3 \%$ and $17.8 \%$ and integral length scales of $0.15 \mathrm{~m}$ and $0.41 \mathrm{~m}$ respectively. It can be seen in Figure 25 that increasing the integral length scale has increased the power and thrust coefficients of the turbine. The increase in power coefficient is over $10 \%$, and considering the turbulence intensity is 3\% higher for the larger length scale case, this suggests that the integral length scale has a much greater effect than the turbulence intensity. As found from previous experiments the length scale to diameter ratio may be an important parameter requiring further investigation with different turbines and turbulence conditions[10].

\section{$+\quad$ Case $2: \ell=0.15 \mathrm{~m} ; I=14.3 \% \quad \bigcirc \quad$ Case $6: \ell=0.41 \mathrm{~m} ; I=17.8 \%$}

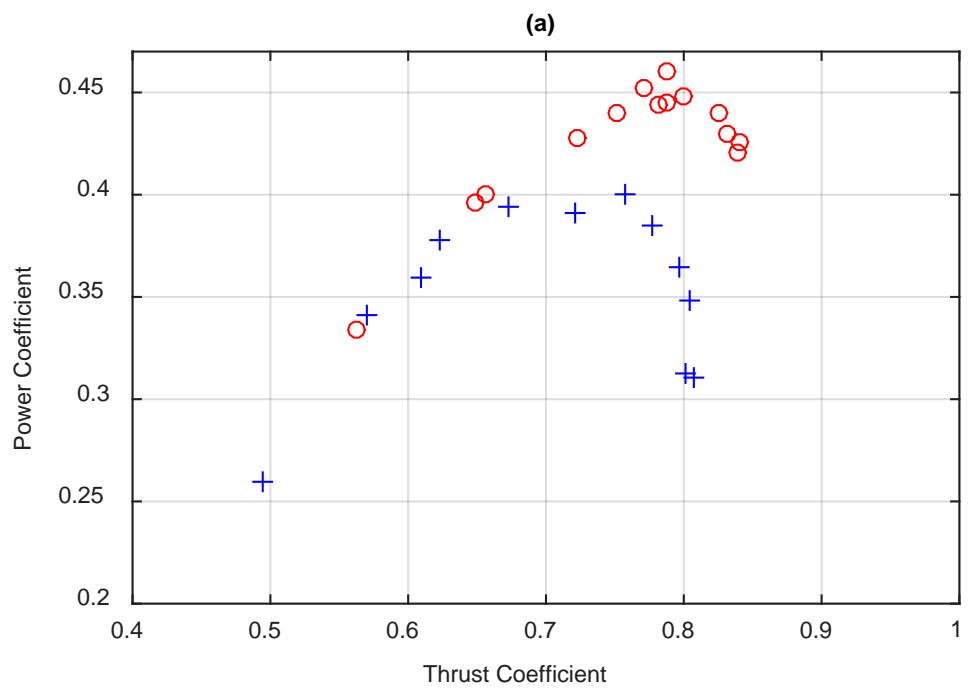

Figure 25 - Power and thrust coefficients for cases 2 (small grid, 3.2m distance) and 6 (large grid, $9.6 \mathrm{~m}$ distance) with integral length scales of $0.15 \mathrm{~m}$ and $0.41 \mathrm{~m}$ respectively.

\subsubsection{Fluctuations in rotor thrust}

The previous section discussed the effects of turbulence intensity and integral length scale on the mean power and thrust. This section considers the effects of turbulence intensity and integral length 
scale on the fluctuations in power and thrust. The fluctuations are expressed as an intensity which is defined as the standard deviation normalised with the mean and expressed as a percentage.

Figure 26 shows the rotor thrust fluctuations; excluding cases 4 (small grid, $8 \mathrm{~m}$ distance) and 5 (large grid, $6.4 \mathrm{~m}$ distance) which are not available due to a technical fault during testing. It can be seen in Figure 26 for case 2 (small grid, $3.2 \mathrm{~m}$ distance) and case 3 (small grid, $4.8 \mathrm{~m}$ distance) with similar length scales and turbulence intensities of $14.3 \%$ and $10.2 \%$ respectively that an increase in turbulence intensity increases the fluctuations in the thrust load. Consider case 2 (small grid, $3.2 \mathrm{~m}$ distance) and case 6 (large grid, $9.6 \mathrm{~m}$ distance) with turbulence intensities of $14.3 \%$ and $17.8 \%$ and integral length scales of $0.15 \mathrm{~m}$ and $0.41 \mathrm{~m}$ respectively. It can be seen that increasing the integral length scale causes a significant increase in thrust fluctuations, greater than expected from the difference in turbulence intensity alone. This is consistent with the findings of the previous section where the integral length scale had the greatest effect on turbine performance.

\begin{tabular}{|c|c|c|c|c|c|c|c|}
\hline$\times$ & $\begin{array}{l}\text { Case } 1 \\
I=4.6 \% \\
\ell=0.76 \mathrm{~m}\end{array}$ & + & $\begin{array}{l}\text { Case } 2 \\
I=14.3 \% \\
\ell=0.15 \mathrm{~m}\end{array}$ & * & $\begin{array}{l}\text { Case } 3 \\
I=10.2 \% \\
\ell=0.18 \mathrm{~m}\end{array}$ & 0 & $\begin{array}{l}\text { Case } 6 \\
I=17.8 \% \\
\ell=0.41 \mathrm{~m}\end{array}$ \\
\hline
\end{tabular}

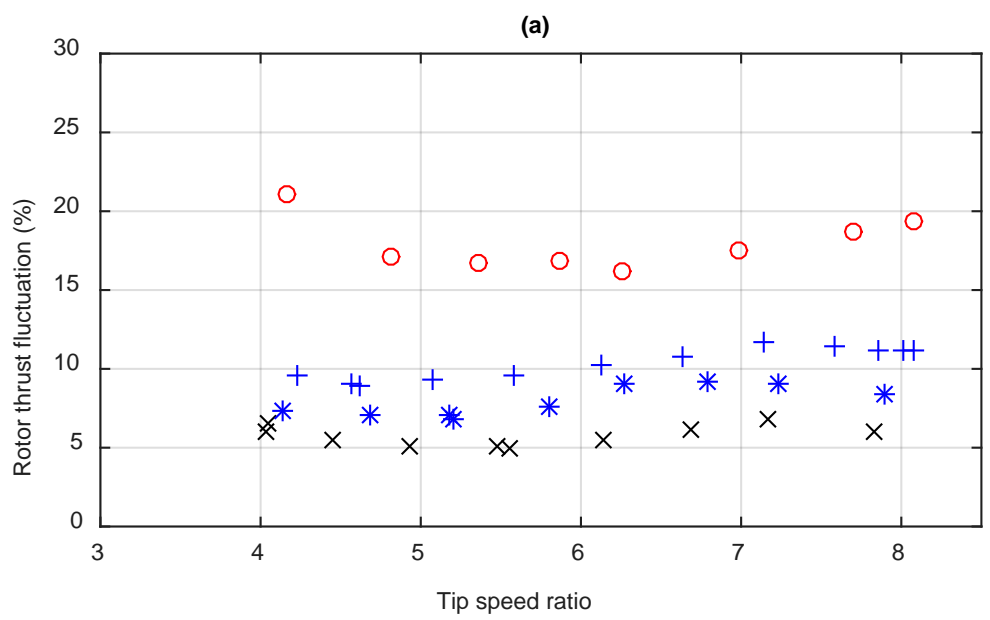

Figure 26 - Fluctuations in rotor thrust (standard deviation normalised by mean thrust) against turbine tip-speed-ratio. Black - no grid, blue - small grid, red - large grid.

Figure 27 shows the fluctuation intensities of rotor torque and rotor thrust for 5 cases averaged over the range $5<\mathrm{TSR}<6$, which corresponds to peak power. It can be seen that the fluctuations in torque range from $11 \%$ to $24 \%$, and the fluctuations in thrust range from $5 \%$ to $17 \%$. The variations in torque fluctuations and thrust fluctuations appear to be directly correlated. This seems reasonable given the forces acting on the blade are generated from the hydrodynamic lift and drag acting perpendicular and parallel to the blade chord respectively. The torque and thrust are then made up of the sine and cosine of the lift and drag, so they are directly linked. 


\begin{tabular}{|c|c|c|c|c|c|c|c|c|c|}
\hline$x$ & $\begin{array}{l}\text { Case } 1 \\
I=4.6 \% \\
\ell=0.76 \mathrm{~m}\end{array}$ & + & $\begin{array}{l}\text { Case } 2 \\
I=14.3 \% \\
\ell=0.15 \mathrm{~m}\end{array}$ & * & $\begin{array}{l}\text { Case } 3 \\
I=10.2 \% \\
\ell=0.18 \mathrm{~m}\end{array}$ & • & $\begin{array}{l}\text { Case } 4 \\
I=6.8 \% \\
\ell=0.22 \mathrm{~m}\end{array}$ & 0 & $\begin{array}{l}\text { Case } 6 \\
I=17.8 \% \\
\ell=0.41 \mathrm{~m}\end{array}$ \\
\hline
\end{tabular}

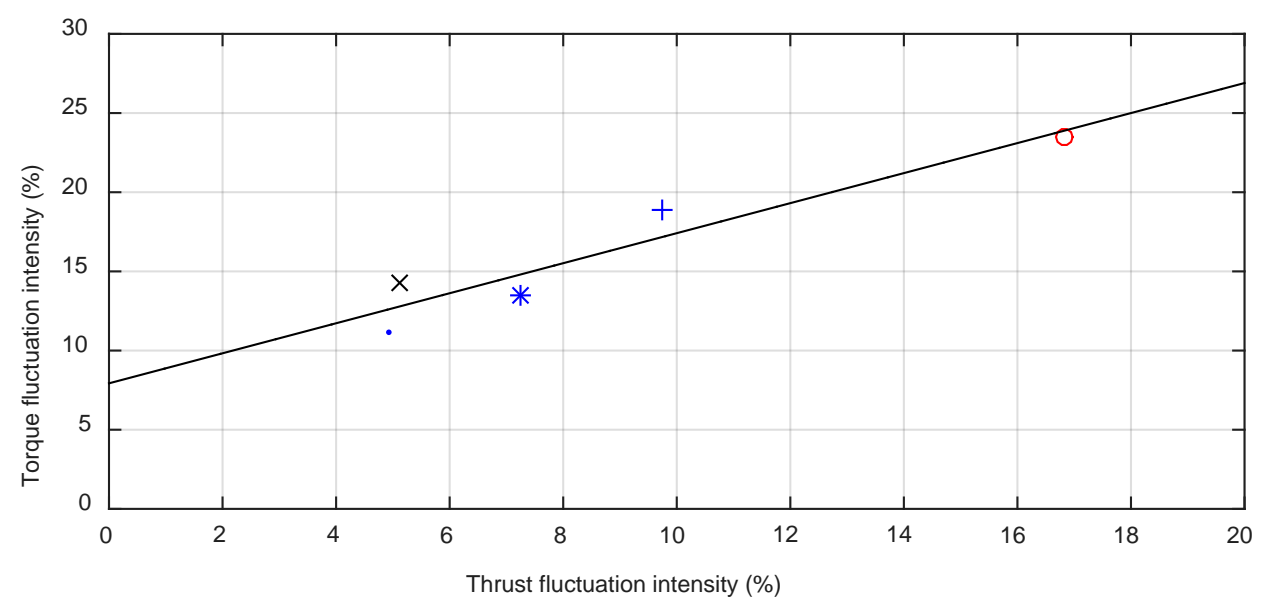

Figure 27 - Turbine thrust and torque fluctuations averaged over $5<$ TSR $<6$. Black - no grid, blue - small grid, red - large grid.

\subsection{Blade root bending moments}

Figure 28 shows the edgewise and flapwise blade root bending moment coefficients across a range of tip-speed-ratios for each of the different cases. The shape and magnitude of these results are consistent with previous investigations of a similar sized turbine in a towing tank [15], [16]. As the tip-speed-ratio is increased the flapwise bending moment increases, in a similar manor to the increase in rotor thrust. However, the edgewise bending moment reduces as the rotor speed increases due to the reduction in torque due to a reduction in angle of attack on the blade with increased rotational speed.

As for the rotor, the blade root bending moment coefficients have been averaged over the peak power range $5<\mathrm{TSR}<6$, and shown in Figure 29 for the edgewise and flapwise root bending moment coefficients. Similar trends are observed as for the rotor in the previous section.

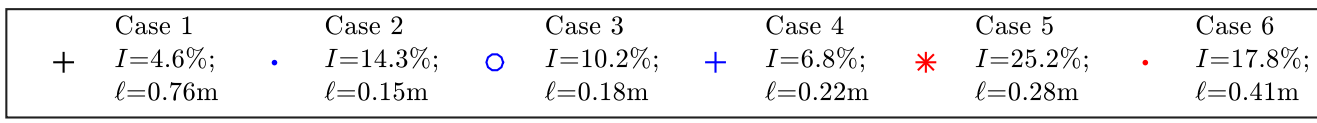

(a)

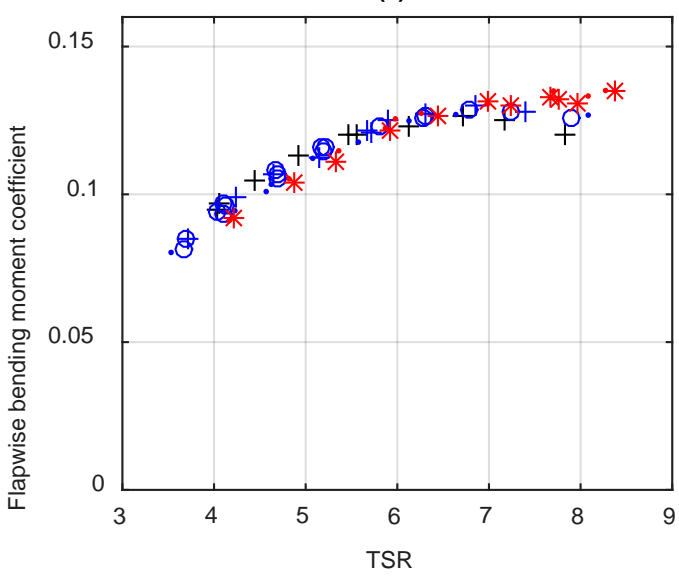

(b)

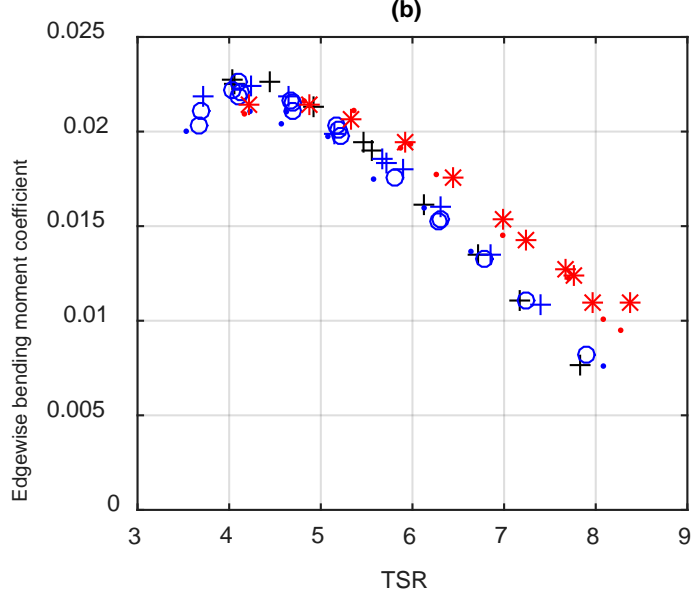

Figure 28 - Flapwise and edgewise blade root bending moment coefficients against turbine tipspeed-ratio. Black - no grid, blue - small grid, red - large grid. 


\begin{tabular}{|c|c|c|c|c|c|c|c|c|c|c|c|}
\hline$x$ & $\begin{array}{l}\text { Case } 1 \\
I=4.6 \% \\
\ell=0.76 \mathrm{~m}\end{array}$ & + & $\begin{array}{l}\text { Case } 2 \\
I=14.3 \% \\
\ell=0.15 \mathrm{~m}\end{array}$ & * & $\begin{array}{l}\text { Case } 3 \\
I=10.2 \% \\
\ell=0.18 \mathrm{~m}\end{array}$ & • & $\begin{array}{l}\text { Case } 4 \\
I=6.8 \% \\
\ell=0.22 \mathrm{~m}\end{array}$ & $\nabla$ & $\begin{array}{l}\text { Case } 5 \\
I=25.2 \% \\
\ell=0.28 \mathrm{~m}\end{array}$ & 0 & $\begin{array}{l}\text { Case } 6 \\
I=17.8 \% ; \\
\ell=0.41 \mathrm{~m}\end{array}$ \\
\hline
\end{tabular}

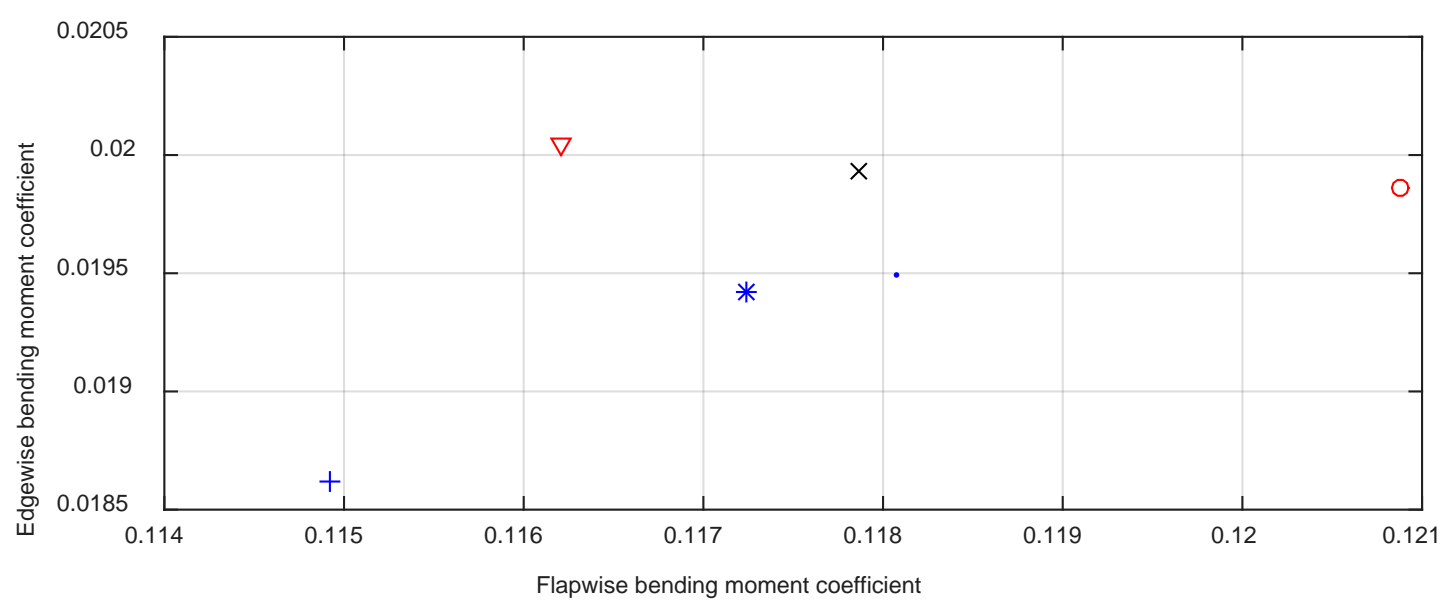

Figure 29 - Flapwise and edgewise blade root bending moment coefficients averaged over $5<$ TSR <6. Black - no grid, blue - small grid, red - large grid.

\subsubsection{Fluctuations in blade root bending moments}

It has been shown how turbulence affects the performance and mean load acting on a rotor blade. However, the real uncertainty thus far is the fatigue loadings and fluctuations in force. Figure 30(a) shows the fluctuation intensity of the flapwise blade root bending moment. It can be seen that at low TSR the fluctuation intensity reduces, with a minimum occurring at around TSR $=4.5$. As TSR increases there is a roughly linear increase in fluctuation intensity. Comparing between the different cases, it can be seen that increasing turbulence intensity results in an increase in fluctuation intensity. Increasing the integral length scale shows a significant increase in fluctuation intensity for cases 5 and 6 . Overall, increasing the turbulence intensity or length scale results in a significant increase in the fatigue loadings. Case 1 (no grid) with low turbulence results in a fluctuating load that is $5-10 \%$ of the mean value. Increasing the turbulence to the most extreme case, case 5 (large grid, $6.4 \mathrm{~m}$ distance), results in fluctuations in mean load of 30-45\%.

Similar trends are observed for the fluctuation intensity of the edgewise blade root bending moment, as shown in Figure 30(b). At high tip-speed-ratios (TSR > 7) the difference in fluctuation intensity of the edgewise blade root bending moment is less pronounced. The fluctuation intensity of the edgewise blade root bending moment is approximately double that of the flapwise blade root bending moment. 


\begin{tabular}{|c|c|c|c|c|c|c|c|c|c|}
\hline+ & $\begin{array}{l}\text { Case } 1 \\
I=4.6 \% \\
\ell=0.76 \mathrm{~m}\end{array}$ & $\begin{array}{l}\text { Case } 2 \\
I=14.3 \% \\
\ell=0.15 \mathrm{~m}\end{array}$ & 0 & $\begin{array}{l}\text { Case } 3 \\
I=10.2 \% \\
\ell=0.18 \mathrm{~m}\end{array}$ & + & $\begin{array}{l}\text { Case } 4 \\
I=6.8 \% \\
\ell=0.22 \mathrm{~m}\end{array}$ & 米 & $\begin{array}{l}\text { Case } 5 \\
I=25.2 \% \\
\ell=0.28 \mathrm{~m}\end{array}$ & $\begin{array}{l}\text { Case } 6 \\
I=17.8 \% ; \\
\ell=0.41 \mathrm{~m}\end{array}$ \\
\hline
\end{tabular}
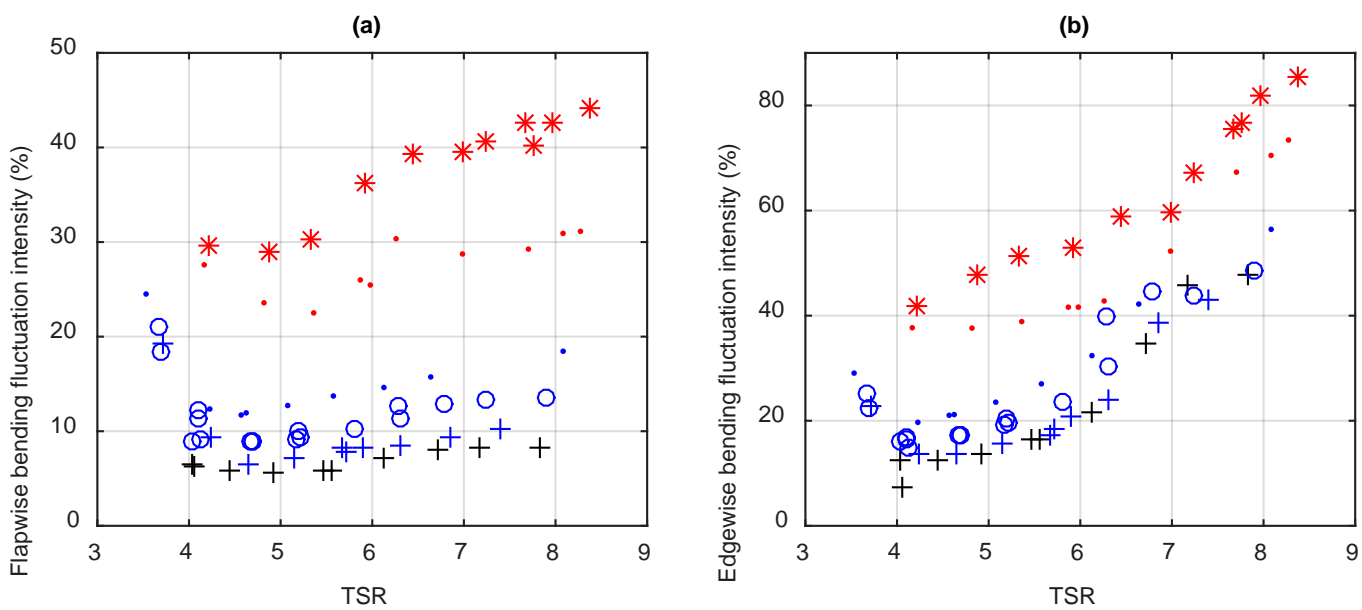

Figure 30 - Fluctuation intensity of flapwise and edgewise blade root bending moment coefficients. Black - no grid, blue - small grid, red - large grid.

As for the blade root bending moment coefficients the fluctuation intensities have been averaged over the range $5<\mathrm{TSR}<6$. Figure 31 shows the flapwise and edgewise blade root bending moment fluctuation intensities plotted against each other for cases 1-6. It can be seen that the fluctuation intensities are directly linked between the flapwise and edgewise blade root bending moments. A linear regression has been performed to provide a very good fit with coefficient of determination of 0.999 . This correlation is due to the lift and drag of the blade hydrofoil contributing to both the flapwise and edgewise blade root bending moments. Therefore any change to the inflow velocity at the blade will result in a change in the lift and/or drag of the blade, which in turn affects the flapwise and edgewise blade root bending moments. However, it does imply that in order to monitor the fatigue loads experienced by a turbine blade it is only necessary to monitor the loads in one direction as they are so strongly linked. This would reduce the required instrumentation, and hence cost. However, this can be taken a step further. Can the fatigue loads experienced by a blade be estimated from fluctuations in rotor torque, or power output?

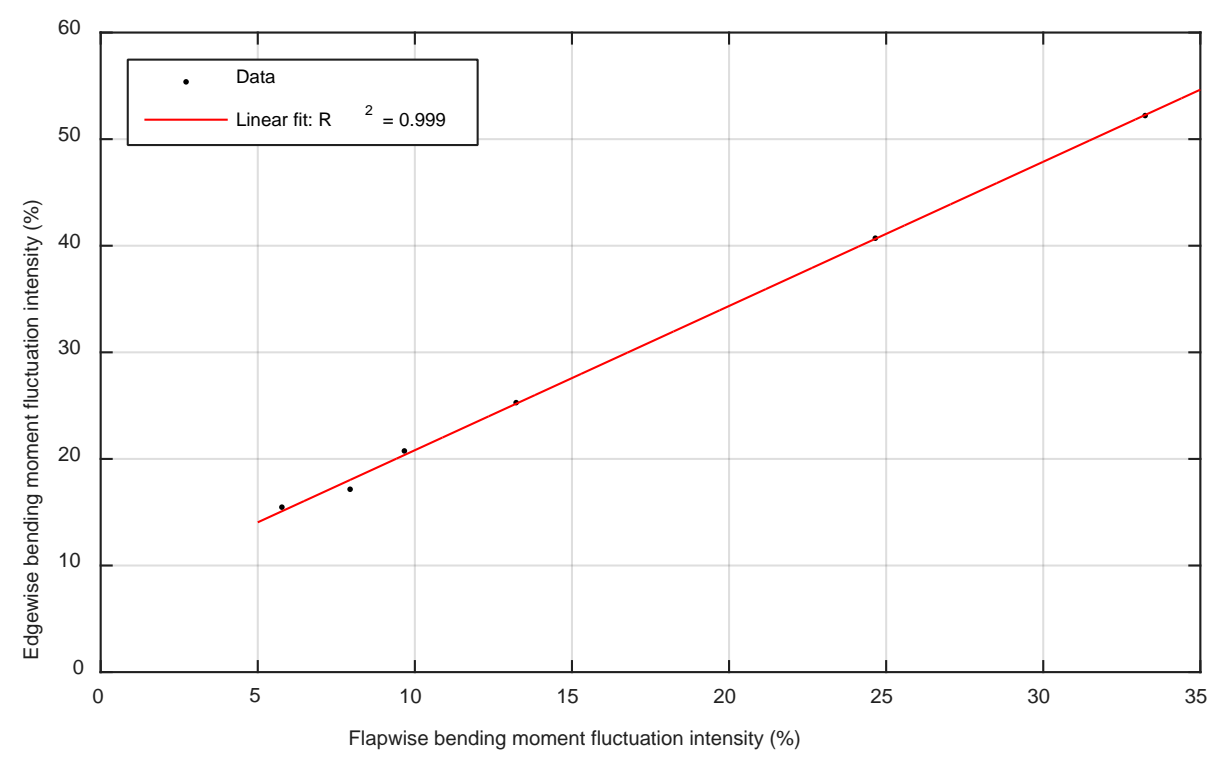

Figure 31 - Flapwise and edgewise blade root bending moment fluctuation intensities averaged over $5<$ TSR $<6$. 


\subsubsection{Comparison between rotor and blade fluctuations}

Figure 32 (a) shows the fluctuation intensity of the rotor thrust and flapwise blade root bending moment averaged over $5<\mathrm{TSR}<6$. It can be seen that a linear relation is observed with a very strong correlation with coefficient of determination of 0.98 . This is consistent with the findings from turbine operation in planar oscillatory flow where a linear relation between rotor thrust and flapwise bending moment was observed [15]. Therefore, if the turbine rotor thrust is measured, accurate estimates of the fatigue loadings experienced by the blades can be made, without the need to instrument the blades, or vice-versa.

The same is also observed for the fluctuation intensities of the rotor torque and edgewise blade root bending moment as shown in Figure 32(b). Again, the rotor and blade fluctuations are strongly correlated with coefficient of determination of 0.82 . As fluctuations in rotor torque would also be experienced by the generator (as they are directly linked), any fluctuation in electrical output of the turbine may also be linked to the fluctuating loads experienced by the blades. It would therefore be possible to estimate the fatigue loads experienced by the turbine blades from fluctuations in power output, without the need to install any instruments on the turbine itself. This is important as the cost of accessing turbines for maintenance is expensive. If the loads experienced by the blades can be monitored in real time, without the need for expensive instrumentation, a fatigue life for the blade may be calculated based on its operational performance. Maintenance can therefore be performed when required to prevent blade failure or premature retrieval of the turbine while it may still have safe operating life.
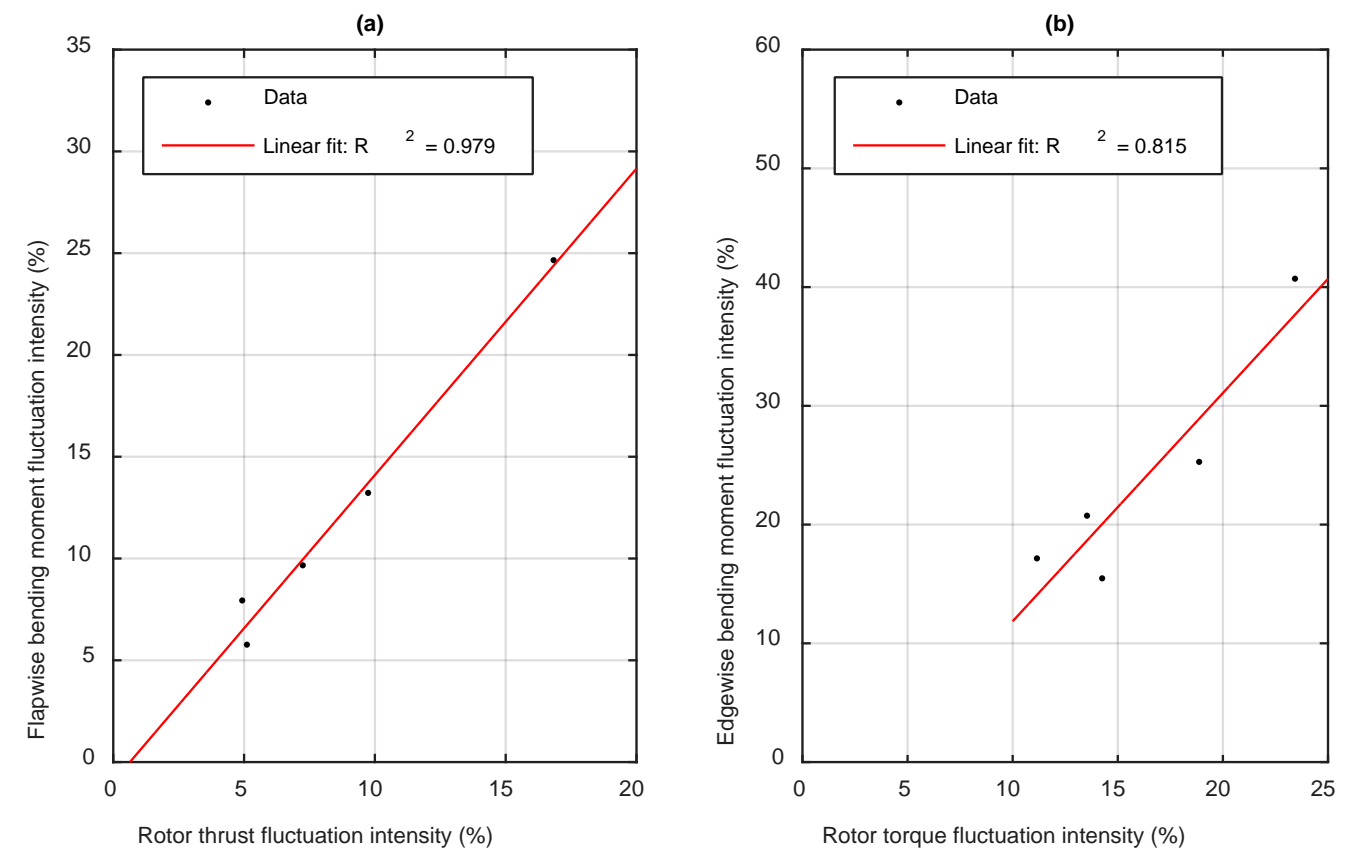

Figure 32 - Fluctuation intensity of (a) rotor thrust and flapwise blade root bending moment, (b) rotor torque and edgewise blade root bending moment.

\subsection{Discussion of Results}

Results have been presented on the performance of a $1 / 20^{\text {th }}$ scale tidal stream turbine operated in turbulent flows with different characteristics. The turbulence characteristics ranged from $\sim 5-25 \%$ turbulence intensity and length scales of $\sim 0.15-0.7 \mathrm{~m}$, corresponding to length scale to turbine diameter ratios of approx. $0.2-1$. The turbulence flows were generated using static grids that generated roughly uniform, isotropic flows and could therefore be considered free-stream conditions. The range of turbulence intensities compare well with site measurements of roughly $10-15 \%$ for the case of a tidal channel and off a headland [8], [9]. However, measurements of length scales show much larger variations between sites from $11-14 \mathrm{~m}$ for a tidal channel [8], to over 100m off a headland [9]. For a turbine rotor of $18 \mathrm{~m}$ diameter the length scale to rotor diameter ratio is $\sim 0.7$ for a tidal channel, which compares well to the conditions used in these experiments. While the turbulence intensities and length scales compare well to those from a tidal channel, a tidal flow is anisotropic (u:v $~ 1: 0.7$ [8]) and non-uniform. Further investigation is therefore required to consider these effects and how site specific flow characteristics may 
be created in a flume. However, it was not our intention to create site specific turbulence in this study, but to generate a range of flows with different turbulence intensities and length scales in order to investigate the specific contribution turbulence has to performance and blade loads.

It was shown that increasing the turbulence intensity reduced the mean thrust and power (Figure 24 ), and is consistent with previous studies that found a $10 \%$ reduction in power and thrust with an increase in turbulence intensity from $\sim 5-15 \%$ [13]. However, it was found that the opposite occurs for increasing length scales which resulted in the power and thrust increasing (Figure 25). Overall variations in peak power coefficient were over 10\%, highlighting the significant impact turbulence has on the power output of a tidal turbine. But the question arises as to why there is this sensitivity, sometimes increasing, and sometimes decreasing power output. It seems likely that the different scales of turbulence will interact with the turbine in different ways. Previous investigations have used solid and porous discs to investigate how turbulence intensities and length scales affect the mean thrust force acting on them. Using wind tunnel experiments the interaction of different scales of turbulence on the mean drag force acting on a bluff body has been investigated [26]. In these experiments it was found that small scale turbulence interacts directly with the shear layer bounding the turbine wake from the freestream flow. On the other hand, large scale turbulence interacts directly with the body itself and the wake as a whole. Similar effects have been found using porous disc rotor simulators [10], and the interaction of turbulence scale with the wake observed using Large Eddy Simulations with actuator discs [11]. It was found that small scale turbulence reduced the velocity deficit in the wake of the actuator disc, but did not significantly affect the wake expansion or wake recovery. However, large scale turbulence resulted in a greater reduction in velocity across the disc, increasing the thrust force, but combined with a higher wake expansion, the wake recovered much faster. It seems likely that the same mechanism is occurring here on the scale tidal turbine. The larger length scales interact directly with the wake causing faster mixing with the high momentum freestream flow, resulting in a faster wake expansion and an increase in power output. However, small scale turbulence is interacting with the shear layer reducing the mixing between the core of the wake and the freestream resulting in a lower velocity drop across the turbine, hence reducing the power output. Increasing the turbulence intensity would therefore increase this entrainment of the wake, reducing the power output. Further work is ongoing to measure the turbine wake in these different turbulence flows to confirm this theory. These results could have a significant impact on the performance of an array of multiple turbines. By careful consideration of the flow characteristics at a site it may be possible to optimise the turbines and their layout to achieve higher power output. It may also be possible to position turbines in such a way to alter the flow characteristics for downstream devices in a beneficial way to increase their power output, and/or reduce their fatigue loads. This could have a large impact on the economic viability of the array.

The other significant effect observed is the increase in force fluctuations with increased turbulence. As the forces acting on the turbine are a function of velocity squared, increasing the fluctuation in the flow would result in much larger fluctuations in force. Therefore increasing intensity for the same length scale would increase the frequency of fluctuation, but with a similar amplitude, and hence a similar increase in force fluctuation. However, increasing the length scale would increase the amplitude of fluctuation and therefore result in a much greater force fluctuation. This is observed in both Figure 27 and Figure 30 for the rotor and blade fluctuations respectively. The main implication of this result is with respect to the fatigue loads experienced by a turbine when installed in a highly turbulent flow. If these fatigue loads are not taken into account the turbine reliability could be significantly reduced, and this could be the reason for a number of device failures [2]-[5]. It is likely that the fatigue loads will be even greater than those measured in this study due to the addition of velocity shear, waves, and anisotropic non-uniform flows at tidal sites. These loads therefore need careful consideration in order to achieve high reliability.

An alternative approach to condition monitoring has also been proposed. It was shown that the forces experienced by the rotor are directly proportional to the blade loads. This finding is consistent with a previous experimental investigation using a similar sized turbine in a towing tank [16]. While there was no direct comparison of rotor and blade loads, it can be seen from their results that the trends observed in the rotor thrust and power coefficients show comparable trends to the edgewise and flapwise blade root bending moment coefficients. The direct link between blade and rotor forces is due to the hydrodynamic lift and drag acting on a blade contributing to both the thrust and torque. Therefore by monitoring the power output of the turbine, accurate estimates of blade loads can be made. This allows real time monitoring of blade loads without the need for additional instrumentation in the turbine, 
allowing maintenance intervals to be optimised based on the fatigue loads experienced by the turbine at reduced capital cost. The requirement for accurate condition monitoring has been investigated by considering the frequency response on the thrust of a model turbine rotor [27]. Blades were offset to simulate a blade fault and it was shown how the frequency response changes compared to normal operating conditions. This same approach could be coupled to our proposal and the output power could be monitored and used to identify faults with blades. Further work is ongoing to increase this dataset across a wider range of conditions to further prove this method.

\section{Conclusions and implications}

This paper presents a method that can be used to generate flows with different turbulence characteristics within a flume. The static grids generate turbulence that decays with distance downstream of the grid and with length scales that are proportional to the grid size. Therefore different turbulence intensities may be generated by changing the downstream distance from the grid, and different length scales may be generated by changing the grid size. The different flows were characterised using high quality measurements from a laser Doppler anemometer. Turbulence intensity, length scales, energy spectra and turbulence dissipation rate were presented.

It was found that the larger grid produced larger integral length scales that increased to $0.41 \mathrm{~m}$, while the smaller grid produced integral length scales that grew to $0.22 \mathrm{~m}$. The integral, dominant and injection length scales were of similar magnitudes and larger behind the large grid than the small grid. However, the integral length scale was chosen for flow mapping as it describes the turbulent eddy size that contains the largest proportion of turbulent energy, and therefore likely to have the greatest effect of turbine performance. The turbulence intensities behind the grids were found to vary from 6.8 to $25.2 \%$ which compares well to tidal sites with intensities of 10-15\%. Larger velocity shear gradients were observed for the large grid than the small grid. Further investigation is required to identify the cause of this, but it is thought that it is due to free surface effects. A $1 / 20^{\text {th }}$ scale $0.8 \mathrm{~m}$ diameter tidal turbine was operated in the observed turbulent flows. The turbine was instrumented to measure overall rotor thrust and torque, flapwise and edgewise blade root bending moments. The turbine was controlled to maintain constant RPM using a fast response electronic load connected to a permanent magnet DC motor generator.

A full summary of the effects of turbulence on a turbines performance is shown in Table 6 . The main findings of this work are:

- Turbulence has a significant effect on the turbine power and thrust coefficients, with variations in excess of $10 \%$.

- Increasing the tip-speed-ratio of the turbine increases the load fluctuations of both flapwise and edgewise blade root bending moment.

- Turbulence has a significant effect on the load fluctuations experienced by the blades with a 5 fold increase in the most extreme case.

- Flapwise and edgewise blade root bending moment fluctuations are directly linked with a linear correlation.

- Rotor fluctuations and blade fluctuations are directly linked with linear correlations.

Table 6 - Summary of findings and the effects of turbulence on a turbines performance.

\begin{tabular}{|c|c|c|c|c|}
\hline Parameter & $\begin{array}{c}\text { Normalisation } \\
\text { velocity }\end{array}$ & Turbulence Intensity, I & Integral length scale, $\ell$ & TSR \\
\hline & $\begin{array}{c}\text { Squaring and cubing } \\
\text { operations should } \\
\text { be performed prior } \\
\text { to temporal and } \\
\text { Rotor power } \\
\text { and thrust } \\
\text { coefficients } \\
\text { avoid overaging to } \\
\text { the performance } \\
\text { coefficients in highly } \\
\text { turbulent flows. In }\end{array}$ & $\begin{array}{c}\text { Increasing turbulence } \\
\text { intensity reduces the } \\
\text { power and thrust } \\
\text { coefficients by over 10\% in } \\
\text { extreme cases. Their } \\
\text { fluctuations also increase. }\end{array}$ & $\begin{array}{c}\text { Increasing integral length } \\
\text { scale increases power and } \\
\text { thrust coefficients by over } \\
10 \% \text {. A larger increase in } \\
\text { fluctuations is also } \\
\text { observed. }\end{array}$ & \\
\hline
\end{tabular}




\begin{tabular}{|c|c|c|c|c|}
\cline { 2 - 3 } $\begin{array}{c}\text { Blade root } \\
\text { bending } \\
\text { moments }\end{array}$ & $\begin{array}{c}\text { extreme cases the } \\
\text { Betz limit may } \\
\text { Otherwise be } \\
\text { 'exceeded'. }\end{array}$ & $\begin{array}{c}\text { Causes a reduction in } \\
\text { flapwise and edgewise } \\
\text { blade root bending } \\
\text { moments, but increases } \\
\text { their fluctuations. }\end{array}$ & $\begin{array}{c}\text { Causes an increase in } \\
\text { flapwise and edgewise } \\
\text { blade root bending } \\
\text { moments with a larger } \\
\text { increase in their } \\
\text { fluctuations. }\end{array}$ & $\begin{array}{c}\text { Increasing the TSR } \\
\text { increases fluctuations } \\
\text { in both flapwise and } \\
\text { edgewise blade root } \\
\text { bending moments. }\end{array}$ \\
\hline \multirow{2}{*}{ Correlations } & \multicolumn{2}{|c|}{ Flapwise and edgewise blade root bending moment fluctuations are directly linked with linear correlation. } \\
\cline { 2 - 3 } & \multicolumn{2}{|c|}{ Rotor fluctuations and blade fluctuations are directly linked with linear correlations. } \\
\hline
\end{tabular}

In addition to the above, a key finding of this work indicates that fluctuations in rotor loading are directly linked to the fluctuations in blade loading. The implication of this finding is that fatigue loads experienced by the turbine blades may be estimated in real time though monitoring the power generated by the turbine. The cost of energy would be reduced as follows:

- Expensive instrumentation installed on the turbine is not required leading to a reduction in capital cost.

- Optimisation of maintenance and operational costs. Turbines could be monitored and only retrieved for maintenance when required, reducing the high costs associated with turbine retrieval, but without risking blade failure.

Further work is underway to validate this concept over a wider range of operating conditions. The authors are currently working to operate the same turbine in a real tidal flow and these datasets will be made available at www.energy.soton.ac.uk.

\section{Acknowledgements}

This work is part of the research programme undertaken by the Sustainable Energy Research Group, at the University of Southampton (www.energy.soton.ac.uk). Some of the work received support from MARINET, a European Community - Research Infrastructure Action under the FP7 "Capacities" Specific Programme with further support from the EPSRC grant 'Reducing the Costs of Marine Renewables via Advanced Structural Materials (ReC-ASM)'- EP/K013319/1.

\section{References}

[1] A. S. Bahaj and L. E. Myers, "Fundamentals applicable to the utilisation of marine current turbines for energy production," Renew. Energy, vol. 28, no. 14, pp. 2205-2211, Nov. 2003.

[2] BBC, "Blade fault on giant tide turbine AK1000 in Orkney," BBC, 2010. [Online]. Available: http://www.bbc.co.uk/news/uk-scotland-highlands-islands-11492829. [Accessed: 07-Dec-2015].

[3] M. Boslet, "A Big Setback for Tidal Power," greentechmedia, 2010. [Online]. Available: http://www.greentechmedia.com/articles/read/a-big-setback-for-tidal-power. [Accessed: 07Dec-2015].

[4] MCT, "Delay in commissioning one of SeaGen's rotors," Marine Current Turbines, 2008. [Online]. Available:

http://www.marineturbines.com/3/news/article/11/delay_in_commissioning_one_of_seagen_s _rotors. [Accessed: 07-Dec-2015].

[5] R. Shulman, "N.Y. Tests Turbines to Produce Power," The Washington Post, 2008. [Online]. Available: http://www.washingtonpost.com/wpdyn/content/article/2008/09/19/AR2008091903729.html. [Accessed: 07-Dec-2015].

[6] A. S. Bahaj, "Generating electricity from the oceans," Renew. Sustain. Energy Rev., vol. 15, no. 7, pp. 3399-3416, Sep. 2011.

[7] A. S. Bahaj and L. E. Myers, "Shaping array design of marine current energy converters through scaled experimental analysis," Energy, vol. 59, pp. 83-94, Sep. 2013.

[8] I. A. Milne, R. N. Sharma, R. G. J. Flay, and S. Bickerton, "Characteristics of the turbulence in the flow at a tidal stream power site," Phil Trans R Soc A, 2013.

[9] J. Thomson, B. Polagye, V. Durgesh, and M. C. Richmond, "Measurements of Turbulence at Two Tidal Energy Sites in Puget Sound, WA," IEEE J. Ocean. Eng., vol. 37, no. 3, pp. 363-374, Jul. 2012. 
[10] T. Blackmore, W. M. J. Batten, G. U. Muller, and A. S. Bahaj, "Influence of turbulence on the drag of solid discs and turbine simulators in a water current," Exp. Fluids, vol. 55, no. 1, p. 1637, Dec. 2014.

[11] T. Blackmore, W. M. J. Batten, and A. S. Bahaj, "Influence of turbulence on the wake of a marine current turbine simulator," Proc. R. Soc. A, vol. 470, 2014.

[12] B. Gaurier, P. Davies, A. Deuff, and G. Germain, "Flume tank characterization of marine current turbine blade behaviour under current and wave loading," Renew. Energy, vol. 59, no. November, pp. 1-12, 2013.

[13] F. Maganga, G. Germain, J. King, G. Pinon, and E. Rivoalen, "Experimental characterisation of flow effects on marine current turbine behaviour and on its wake properties," IET Renew. Power Gener., vol. 4, no. 6, p. 498, 2010.

[14] P. Mycek, B. Gaurier, G. Germain, G. Pinon, and E. Rivoalen, "Experimental study of the turbulence intensity effects on marine current turbines behaviour. Part I: One single turbine," Renew. Energy, vol. 66, pp. 729-746, Jun. 2014.

[15] I. a. Milne, a. H. Day, R. N. Sharma, and R. G. J. Flay, "Blade loads on tidal turbines in planar oscillatory flow," Ocean Eng., vol. 60, pp. 163-174, 2013.

[16] I. a. Milne, a. H. Day, R. N. Sharma, and R. G. J. Flay, "Blade loading on tidal turbines for uniform unsteady flow," Renew. Energy, vol. 77, pp. 338-350, 2015.

[17] M. S. Mohamed and J. C. LaRue, "The decay power law in grid-generated turbulence," J. Fluid Mech., vol. 219, pp. 195-214, 1990.

[18] P. A. Krogstad and P. A. Davidson, "Is grid turbulence Saffman turbulence?," J. Fluid Mech., vol. 642, p. 373, Dec. 2009.

[19] S. B. Pope, Turbulent Flows. Cambridge University Press, 2000.

[20] A. G. Roy, T. Buffin-Blanger, H. Lamarre, and A. D. Kirkbride, "Size, shape and dynamics of large-scale turbulent flow structures in a gravel-bed river," J. Fluid Mech., vol. 500, pp. 1-27, 2004.

[21] P. W. Galloway, L. E. Myers, and A. S. Bahaj, "Quantifying wave and yaw effects on a scale tidal stream turbine,” Renew. Energy, vol. 63, pp. 297-307, Mar. 2014.

[22] ITTC, "Recommended Procedures and Guidelines; Uncertainty Analysis, Instrument Calibration," 2008.

[23] D. A. Doman, R. E. Murray, M. J. Pegg, K. Gracie, C. M. Johnstone, and T. Nevalainen, "Towtank testing of a $1 / 20$ th scale horizontal axis tidal turbine with uncertainty analysis," Int. J. Mar. Energy, vol. 11, pp. 105-119, 2015.

[24] T. Burton, D. Sharpe, N. Jenkins, and E. Bossanyi, Wind Energy Handbook: Aerodynamics of Horizontal-Axis Wind Turbines, 2nd ed., vol. 2. Chichester, UK: John Wiley \& Sons, 2001.

[25] a. Mason-Jones, D. M. O’Doherty, C. E. Morris, T. O’Doherty, C. B. Byrne, P. W. Prickett, R. I. Grosvenor, I. Owen, S. Tedds, and R. J. Poole, "Non-dimensional scaling of tidal stream turbines," Energy, vol. 44, no. 1, pp. 820-829, 2012.

[26] Y. Nakamura and Y. Ohya, "The effects of turbulence on the mean flow past two-dimensional rectangular cylinders," J. Fluid Mech., vol. 149, pp. 255-273, Apr. 1984.

[27] R. I. Grosvenor, P. W. Prickett, C. Frost, and M. Allmark, "Performance and Condition Monitoring of Tidal Stream Turbines," in European Conference of the Prognostics and Health Management Society, 2014, pp. 543-551.

\section{Appendix}

Static grid used to generate turbulence in the IFREMER circulating water flume. 


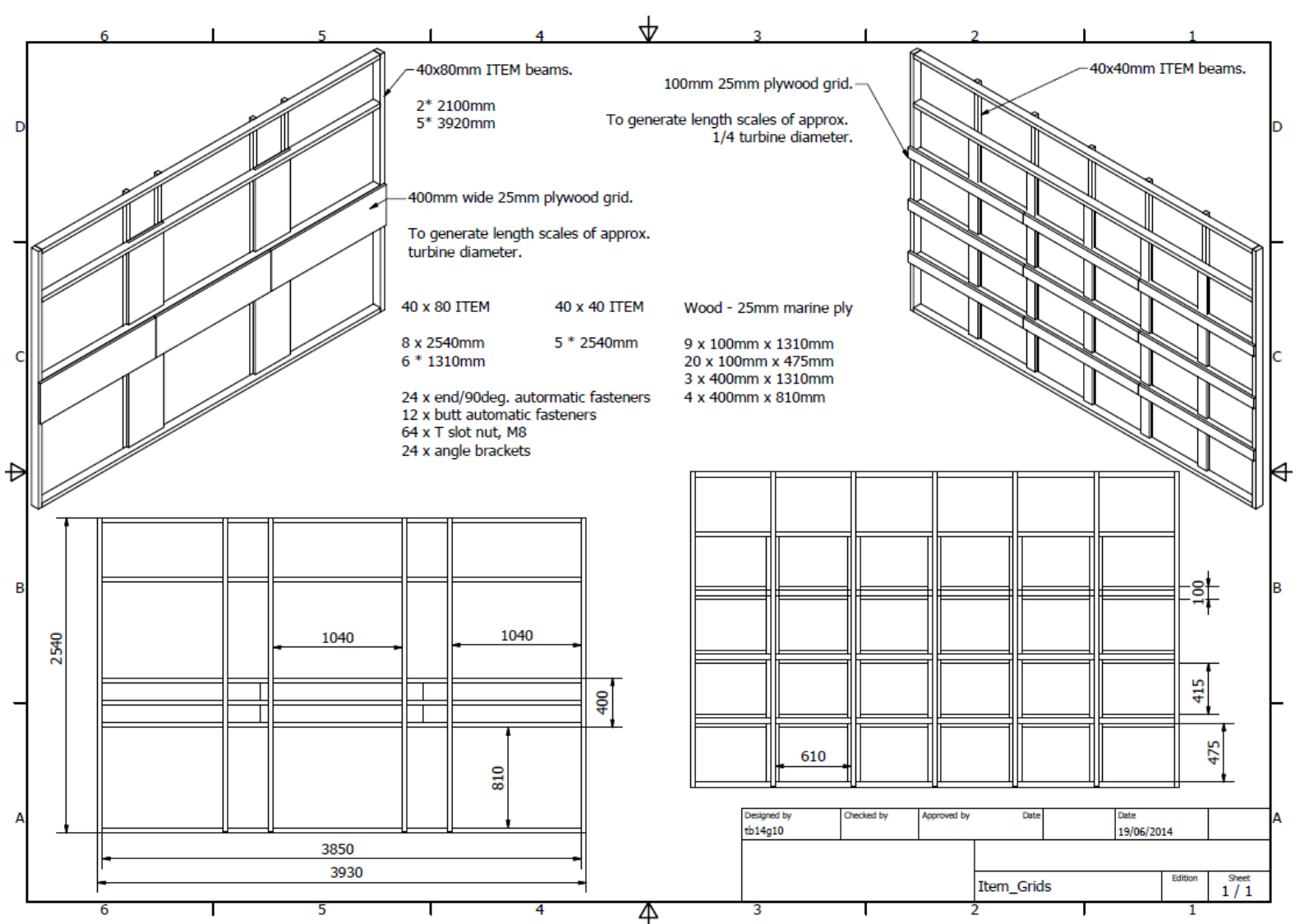

Figure 33 - Static grids used to generate turbulence in the IFREMER circulating water flume. 